\title{
Multi-locus phylogenies reveal three new truffle-like taxa and the traces of interspecific hybridization in Octaviania (Boletales)
}

Takamichi Orihara ( $\boldsymbol{\nabla}$ t_orihara@nh.kanagawa-museum.jp)

Kanagawa Prefectural Museum of Natural History https://orcid.org/0000-0002-0409-7810

Rosanne Healy

University of Florida Department of Plant Pathology

Adriana Corrales

Universidad Del Rosario

Matthew E. Smith

University of Florida Department of Plant Pathology

\section{Research}

Keywords: Boletaceae, hypogeous fungi, phylogeography, sequestrate fungi, systematics, 3 new taxa

Posted Date: September 3rd, 2020

DOI: https://doi.org/10.21203/rs.3.rs-71134/v1

License: (c) (i) This work is licensed under a Creative Commons Attribution 4.0 International License. Read Full License 


\section{Abstract}

Among many convergently evolved sequestrate fungal genera in Boletaceae(Boletales, Basidiomycota), the genus Octaviania is the most diverse. We recently collected many specimens of Octaviania subgenus Octaviania, including several undescribed taxa, from Japan and the Americas. Here we describe two new species in subgenus Octaviania, $O$. tenuipes and 0 . tomentosa, from temperate to subtropical evergreen Fagaceae forests in Japan based on morphological observation and robust multi-locus phylogenetic analyses (nrDNA ITS and partial large subunit [LSU], translation elongation factor 1-a gene [TEF1] and the largest subunit of RNA polymerase II gene [RPB1]). Based on specimens from the Americas as well as studies of the holotype, we also taxonomically re-evaluate the taxon 0 . asterosperma var. potteri. Our analysis suggests that $O$. asterosperma var. potteri is a distinct taxon within the subgenus Octaviania so we recognize this as $O$. potteri. We unexpectedly collected $O$. potteri specimens from geographically widespread sites in the USA, Japan and Colombia. This is the first verified report of Octaviania from the South American continent. Our molecular analyses also revealed that the RPB1 sequence of one $O$. tenuipes specimen was identical to that of a closely related species, $O$. japonimontana, and that one $O$. potteri specimen from Minnesota had an RPB1 sequence of an unknown species of 0 . subg. Octaviania. Additionally, one $O$. japonimontana specimen had an unusually divergent TEF1 sequence. Gene-tree comparison and phylogenetic network analysis of the multi-locus dataset suggest that these heterogenous sequences are most likely the result of previous inter- and intra-specific hybridization. We hypothesize that frequent hybridization events in Octaviania may have promoted the high genetic and species diversity within the genus.

\section{Introduction}

The Boletaceae (Boletales, Basidiomycota) is generally recognized as a large family that consists of epigeous, mushroom-forming fungi. However, recent systematic studies have revealed a considerable number of sequestrate (truffle-like and secotioid) fungal lineages in the family that have evolved independently from boletoid mushrooms (e.g., Castellano et al. 2016; Desjardin et al. 2008, 2009; Lebel et al. 2012a, 2012b; Nuhn et al. 2013; Orihara et al. 2010, 2016a, 2016b; Orihara and Smith 2017; Smith et al. 2015, 2018; Sulzbacher et al. 2020; Vadthanarat et al. 2018; Wu et al. 2016). Although many sequestrate genera in Boletaceae comprise one or a few species, the genus Octaviania Vittad. (orthographic variant: Octavianina Kuntze; Boletaceae, Boletales), which belongs to the subfamily Leccinoideae (Wu et al. 2014), is exceptionally diverse and includes more than 25 truffle-like species (Orihara et al. 2012a; Paz et al. 2014, 2016).

The genus Octaviania is comprised of sequestrate, truffle-like species that have a marbled gleba and dextrinoid or non-amyloid basidiospores with coarse, conical to pyramidal ornamentation (Orihara et al. 2012a). Historically, the generic concept of Octaviania was unsettled and the genus was previously considered by some authors as a synonym of Arcangeliella Cavara (Russulaceae), Hydnangium Wallr (Hydnangiaceae). or Melanogaster Corda (Paxillaceae). Pegler and Young (1979) provided evidence that Octaviania is distinct from those morphologically similar sequestrate genera and Orihara et al (2012a) 
redefined the current generic concept of the genus. Orihara et al. (2012a) further divided the genus into three subgenera, subg. Octaviania, Fulvoglobus Orihara and Parcaea Orihara, based on multigene phylogenies and the morphology of basidiomata. Paz et al. (2016) reviewed the European species of Octaviania and critically examined the type species, 0 . asterosperma. They found that $O$. asterosperma senus stricto has a pseudoparenchymatous peridium, which is one of the major characteristics of subg. Fulvoglobus. Accordingly, they concluded that the subg. Fulvoglobus that was introduced by Orihara et al (2012a) should be synonymized with subg. Octaviania sensu Paz et al. (2016), and that the preceding subg. Octaviania sensu Orihara et al. (2012a) should be synonymized with subg. Mutabiles Paz \& J.M. Vidal.

Octaviania subg. Octaviania sensu Paz et al. (2016) (hereafter referred to simply as Octaviania subg. Octaviania) is characterized by cavities in the gleba filled with slightly viscid to dry, brown to blackish brown spore masses, and a peridium composed of inflated hyphae and isodiametric, pseudoparenchymatous cells. So far, the subgenus accommodates eight described species that are known only from the northern hemisphere (Orihara et al. 2012a; Paz et al. 2016). Orihara et al. (2012a) further suggested that there were at least two additional, taxonomically unsettled species (Octaviania sp. "E" from Japan and Octaviania sp. from North America). Since the publication of Orihara et al. (2012a), we have collected a number of additional specimens of $O$. subg. Octaviania from Japan, including the two species mentioned above. In addition, we collected fruitbodies of $O$. subg. Octaviania from a Quercus humboldtii forest in Colombia, which constitutes the first known record of Octaviania sensu stricto from South America. Our primary research objective is to clarify the phylogenetic and systematic positions of those taxonomically unsettled specimens in a robust phylogenetic framework. Here we propose two new species and one new taxonomic status based on morphological observations and nuclear multi-locus phylogenies. Furthermore, we found strong topological conflicts in some species of 0 . subg. Octaviania among gene trees. We therefore examined the cause of these conflicts based on gene-tree comparisons and phylogenetic network analyses and we discuss the possibility of inter- and intra-specific hybridization within the subgenus based on their ecology and phylogeography.

\section{Methods}

Taxon sampling and morphological observation

Fresh basidiomata were collected throughout Japan, from eastern North America and from Colombia, South America. After morphological observation the fruitbodies were air-dried or freeze-dried and then stored in sterile plastic bags. These specimens are deposited in Kanagawa Prefectural Museum of Natural History, Japan (KPM), Ada Hayden Herbarium, lowa State University (ISC), Bell Museum of Natural History Herbarium Fungal Collection, University of Minnesota (MIN), Farlow Herbarum, Harvard University (FH), Florida Museum of Natural History Fungal Herbarium, University of Florida (FLAS), and the Oregon State University Herbarium (OSC). Herbarium specimens were obtained from KPM, FLAS, ISC, OSC and the University of Michigan Herbarium (MICH). 
For microscopy, hand-cut sections of fresh or dried specimens were mounted in water, $3 \% \mathrm{KOH}$ or lactoglycerol. To determine amyloidity of basidiospores, dried material was stained with Melzer's reagent. Basidiospore dimensions (range of spore length, from the hilar appendage to the spore tip $\times$ spore width), their standard deviations (SD) and the length to width ratio $(Q)$ were determined based on 50 random measurements unless otherwise mentioned. The $95 \%$ prediction intervals of basidiospore diameter are shown without parentheses in taxonomic descriptions. Both endpoints of the spore dimensions are shown in parentheses, but when the value is the same as the $95 \%$ prediction interval, only the latter is shown. Measurements include the hilar appendage but not the spore ornamentation or pedicel. Basidium sizes are presented as the range of the lengths $\times$ the range of the widths. Scanning electron microscopy (SEM) was performed with the HITACHI TM-4000Plus Tabletop Microscope (Hitachi High-Technologies Co. Ltd., Japan). Small fragments of a dried gleba were excised and immersed in $8 \%$ ionic liquid (1-ethyl3-methyl-imidazolium tetrafluoroborate) for conductive treatment (Yanaga et al., 2012) and were observed at $10-15 \mathrm{kV}$.

DNA extraction, PCR amplification and sequencing

DNA was extracted from fresh or dried fruitbodies using Indicating FTA Cards (Whatman International Ltd, Maidstone, England) based on the protocol by Orihara et al. (2012a, b). We also extracted genomic DNA from some fruitbodies using the protocol of Izumitsu et al. (2012). PCR amplification of the ITS and the large subunit (LSU; 28S) of the nuclear ribosomal DNA (nrDNA), and TEF1 followed Orihara et al. (2012a). For RPB1 amplification, we used a newly designed primer set based on sequences of Boletaceae deposited in the International Nucleotide Sequence Databases (INSD). The new primers include forward primer RPB1-TO-Bf (5'-AAGGCYGATATYGTGAGTC - 3'), which is located in the intron A between domains $\mathrm{A}$ and $\mathrm{B}$ of $R P B 1$, reverse primer RPB1-TO-Br (5'- GCTTTGATGATRTCYCC - $3^{\prime}$ ), and reverse primer RPB1TO-Br2 (5'- ARGCYTTGATRATRTCYCC- $3^{\prime}$ ). Both of the reverse primers are located in the conserved (exon) domain $C$. These primer pairs target an 850-1100 bp amplicon which spans the region between primer RPB1-Bf (Nuhn et al, 2013) and primer RPB1-Cr (Matheny et al., 2002). The PCR amplification of RPB1 was performed using the following procedure: initial incubation at $95^{\circ} \mathrm{C}$ for $10 \mathrm{~min}$; subsequent step of 30 cycles at $94^{\circ} \mathrm{C}$ for $30 \mathrm{~s}, 53^{\circ} \mathrm{C}$ for $60 \mathrm{~s}$, and $72{ }^{\circ} \mathrm{C}$ for $90 \mathrm{~s}$, followed by 13 cycles at $94{ }^{\circ} \mathrm{C}$ for $30 \mathrm{~s}$, $52{ }^{\circ} \mathrm{C}$ for $60 \mathrm{~s}$, and $72{ }^{\circ} \mathrm{C}$ for $90 \mathrm{~s}$; a final elongation step at $72{ }^{\circ} \mathrm{C}$ for $7 \mathrm{~min}$. Unidirectional sequencing of the PCR products in the forward and reverse directions were completed according to Orihara et al. (2012a). Sequences were edited and assembled with Sequence Scanner v. 1.0 (Applied Biosystems, Foster City, California, USA), BioEdit version 7.0.9 (Hall 1999) and SeaView version 4 (Galtier et al. 1996). A total of 178 newly obtained sequences were deposited in INSD (Table 1).

Phylogenetic analyses

For the combined ITS-nLSU-TEF1-RPB1 dataset, we retrieved 170 sequences from INSD (Table 1). The sequences were carefully selected so that the dataset could represent all genera and subgenera in the subfamily Leccinoideae, which includes the genera Chamonixia, Leccinellum, Leccinum, Octaviania, Rossbeevera and Turmalinea (Orihara et al. 2016a). We selected Spongispora temasekensis, 
Spongiforma thailandica, Borofutus dhakanus, Tylocinum griseolum, Binderoboletus segoi and Retiboletus spp. in subfamily Leccinoideae as outgroup taxa based on Henkel et al. (2016) and Wu et al. $(2016,2018)$. We only included specimens in our analysis whose nucleotide sequences covered more than $50 \%$ of the total length of the aligned, full ITS-nLSU-TEF1-RPB1 dataset to reduce a negative effect caused by the lack of sequences in the dataset (i.e., no less than 1802 bp in length in the concatenated 4gene dataset). Accordingly, we could not include sequences of lonosporus, Rhodactina,

Pseudoaustroboletus and two of the polyphyletic clades of Leccinum in the Leccinoideae previously shown in Kuo and Ortiz-Santana (2020) (i.e., the Leccinum talamancae and L. Iongicurvipes lineages). Similarly, several species of Octaviania, including $O$. asterosperma s. str. and $O$. arbucalensis, which belong to subg. Octaviania (Yang et al. 2006; Vadthanarat et al. 2017), were not included in the analyses due to insufficient number of DNA loci available from INSD. Instead, we prepared an additional singlegene $\mathrm{nLSU}$ dataset that included as many Octaviania species as possible available from INSD, including the type species 0 . asterosperma s. str. (Table 1 ). The ML analyses were conducted with RAxML 8.2.10 (Stamatakis, 2014) under the GTR + I + G model. The BioNJ analyses were conducted with SeaView version 4 (Gouy et al., 2010). Sequence alignment was performed with the online version of MAFFT version 7 (Katoh and Standley 2013) under default settings (i.e., the alignment algorithm is automatically selected from FFT-NS-1, FFT-NS-2, FFT-NS-i or L-INS-i). Subsequently, the sites with obvious alignment errors were manually adjusted in SeaView version 4 . We referred to the results of the GBlocks option in SeaView (Castresana 2000) to exclude ambiguously aligned sites. Accordingly, the longest part of the insert within the ITS2 region found in all known species of $O$. subg. Octaviania (Orihara et al. 2012a) was excluded from our analyses. Prior to the multigene analyses, we compared the BioNJ tree topologies among the ITS, $\mathrm{nLSU}, T E F 1$ and RPB1 datasets to see if there were any topological conflicts among the gene trees. Sequences that caused considerable topological conflicts (BioNJ bootstrap values $\geq 75 \%$; 1000 replicates) among the four single-locus phylogenies were excluded from the multi-locus analyses. Accordingly, RPB1 sequences of "Octaviania tenuipes" nom. prov. KPM-NC 27968 (INSD acc. no.: MT868858) and "Octaviania potter" nom. prov. KPM-NC 17828 (MT868837 \& MT868838), that are proposed as new taxa in this study were omitted from the combined multi-locus dataset. We subsequently concatenated the four datasets for the multi-locus analyses. The ITS rDNA region was partitioned by ITS1 + ITS2 and 5.8S, and the TEF1 and RPB1 regions were partitioned by codons and introns, and best-fit likelihood models were estimated for each partition and nLSU with MrModeltest 2.3 (Nylander 2004).

Bayesian analyses were conducted with MrBayes 3.2 (Ronquist and Huelsenbeck 2003). Nucleotide substitution models for maximum likelihood (ML) analyses were selected by the Akaike Information Criterion (AIC) in jModeltest2 (Darriba et al., 2012; Guindon and Gascuel 2003). The GTR $+I+G$ model was applied to ITS1 + ITS2, nLSU, the second codon of RPB1 and the first and third codons of TEF1; SYM + I for $5.8 \mathrm{~S}$ rDNA; F81 + I for the second codon of TEF1; HKY + I for the first codon of RPB1; HKY + G for the third codon of RPB1; and HKY $+\mathrm{I}+\mathrm{G}$ for the introns of TEF1 and RPB1. Bayesian posterior probabilities (PP) were estimated by the Metropolis-coupled Markov chain Monte Carlo method (Geyer 1991). In the multi-gene (ITS + nLSU + TEF1 + RPB1) analysis, two parallel runs were conducted with one 
cold and seven heated chains each for $4 \mathrm{M}$ generations. The parameter for temperature of the seven heated chains in both runs was set to 0.10 . The 0.10 heating scheme was used instead of the default 0.20 setting, because in previous phylogenetic studies on the Leccinoideae, the Markov chains with the 0.10 heating setting converged more smoothly and were less likely to become trapped at local optima (Orihara et al. 2016a; Orihara and Smith 2017). Trees were saved to a file every 1000th generation. We determined that the two runs reached convergence when the average standard deviation of split frequencies (ASDSF) was continuously lower than 0.01. The ASDSF was monitored every 5000 generations. We also verified the convergence by checking that the effective sample size (ESS) of each resulting statistic was sufficiently large (>200). Trees obtained before reaching convergence were discarded as the burn-in, and the remaining trees were used to calculate a $50 \%$ majority consensus topology and to determine PP values for individual branches.

Maximum likelihood (ML) analyses were conducted with RAxML 8.2.10. The same partitioned datasets as those for the Bayesian analyses were used so that different a-shape parameters, GTR rates, and empirical base frequencies could be assigned to each partition. The best-fit ML tree was estimated under the GTRCAT + I model. The rapid bootstrap (BS) analysis was implemented with 1000 replicates.

The single-gene nLSU phylogenies that included all the representative species of Octaviania available from INSD were estimated using the ML and BioNJ methods. The ML analysis was conducted using RAxML 8.2.10, setting the substitution model to GTRCAT + I and the number of rapid BS replicates to 1000. The BioNJ analysis was done by SeaView version 4 with the number of BS replicates set to 1000 .

To compare tree topologies and examine precise phylogenetic placement of our three target taxa in Octaviania subg. Octaviania, we further inferred $\mathrm{ML}$ gene trees from individual ITS, $\mathrm{nLSU}, R P B 1$, and TEF1 datasets of the subgenus using RAxML 8.2.10. The datasets were partitioned by genes for ITS (i.e., ITS1 + ITS2 and 5.8) and by codons for RPB1 and TEF1. The best-fit ML tree was estimated under the GTRCAT + I model. The rapid BS analysis was implemented with 1000 replicates.

Since the comparison of the four gene trees of Octaviania subg. Octaviania detected several heterogenous sequences in the RPB1 and TEF1 regions, we further conducted phylogenetic network analysis based on a smaller multi-locus dataset to find the traces of reticulate evolution among infrageneric taxa in the subgenus Octaviania. The dataset for this analysis included 1-2 representative specimens for each species of the subgenus Octaviania. We selected specimens for which molecular data were available from all four DNA regions (i.e., ITS, $\mathrm{nLSU}, R P B 1$ and TEF1). The RPB1 sequences of "Octaviania tenuipes" nom. prov. (MT868858 [KPM-NC 27968]) and "Octaviania potteri" nom. prov. (seq1: MT868837 [KPM-NC 17828; RH1181]), which were omitted in the multi-gene Bayesian and ML analyses discussed above, were included in the combined dataset for this analysis. The analysis was executed with SplitsTree 4 (Huson and Bryant 2006). Networks were constructed by the NeighborNet method using the "distance estimation to uncorrected $\mathrm{P}$ value" setting. The resultant networks were displayed with the EqualAngle algorithm (Dress and Huson 2004). Bootstrap analysis was then conducted with 1000 replicates. 


\section{Results}

Morphological evaluation of the North American Octaviania species in subgenus Octaviania.

The phylogenetic analyses in Orihara et al. (2012a) explicitly showed that three specimens of Octaviania (KPM-NC 17827, KPM-NC 17828 and OSC 13925) from eastern North America (i.e., lowa, Minnesota and Florida) formed a distinct clade within Octaviania subg. Octaviania but there was no molecular taxonomic treatment of the unidentified taxon. We critically examined the morphology and habitat of the taxon and we compared it with the previously published literature on North American Octaviania species.

The overall macro-morphology, peridial structure and the basidiospore and basidia dimensions matched the original description of Octaviania asterosperma var. potteri Singer and Smith (Singer and Smith 1960), which was reported from Michigan, USA (see description of $O$. potteri below). We studied the holotype of 0 . asterosperma var. potteri (MICH 12376 [Potter 8898]) from the University of Michigan Herbarium (MICH). The specimen was well-preserved, but the cells of the peridium were collapsed. The basidiospore morphology matched those of the three North American specimens of Octaviania sp. (Table 2). We therefore identify the North American Octaviania species as 0 . asterosperma var. potteri. Below we propose a new status for this species as Octaviania potteri stat. nov.

Phylogenetic placement of new taxa inferred from the multi-locus phylogeny

The multi-locus dataset comprised of ITS and LSU nrDNA, TEF1 and RPB1 sequences of the Leccinoideae consisted of 94 specimens and 3603 aligned nucleotide positions. The Bayesian inference reached convergence after ca. $1.38 \mathrm{M}$ generations. Accordingly, we discarded the first 1400 trees in each parallel run, and the remaining 2601 trees in each run were summarized to approximate Bayesian posterior probabilities (PPs). ESS of all the model parameters were sufficiently large $(>200)$. The total arithmetic and harmonic mean of estimated marginal log likelihoods ( $\mathrm{InL}$ ) for runs were -27576.51 and - 27653.13, respectively. In the RAxML analysis, the final ML optimization of log likelihood was 27424.085894. The overall topologies between the Bayesian and ML trees were nearly identical.

The resulting phylogenetic trees (Fig. 1) robustly recovered the known generic relationships within the Leccinoideae, some with higher statistical support than in previous studies (e.g., / Spongiforma-BorofutusTylocinum clade; Wu et al 2016, / Leccinum-Leccinellum-Turmalinea-Rossbeevera clade: Wu et al. 2018; Orihara et al. 2016a; Kuo and Ortiz-Santana 2020). Octaviania sp. " $E$ " (= O. tenuipes sp. nov.) from Japan and $O$. asterosperma var. potteri from North America $(=0$. potteri stat. nov.) were placed within Octaviania subg. Octaviania, as was previously shown by Orihara et al. (2012a). A previously unknown species-level clade (= 0 . tomentosa sp. nov.) was also placed within Octaviania subg. Octaviania.

Specimens of $O$. tenuipes sp. nov. exhibited minimal infraspecific genetic divergence. In contrast, both $O$. potteri stat. nov. and $O$. tomentosa sp. nov. showed considerable genetic divergence among specimens. In the $O$. tomentosa clade, a specimen from Amami-oshima Island in the Ryukyu island chain, was genetically divergent from the other specimens from mainland Japan. In the $O$. potteri stat. nov. clade, the 
geographically isolated specimens from Hokkaido, Japan (KPM-NC 18032) and Colombia (HUA 222100) were nested among the North American specimens.

Although the generic type species, $O$. asterosperma, was not included in the multi-locus phylogenies, the nLSU gene tree indicate that $O$. potteri stat. nov. is genetically distant from $O$. asterosperma var. asterosperma and it should be treated as a distinct taxon (Fig. S1; the InL of the ML tree $=-3239.444877$ ).

Comparison of single-gene tree topologies within Octaviania subgenus Octaviania

The four ML gene trees based on ITS nrDNA (ITS1-5.8S-ITS2), LSU nrDNA, RPB1 and TEF1 datasets were estimated with the final ML optimization of InL of -1806.362004, -1975.613722, -2139.994105 and 2417.247141, respectively (Fig. 2). All of the species-level clades in subg. Octaviania except 0 . potteri stat. nov. were recovered in each tree with high bootstrap values.

Interestingly, one 0 . tenuipes specimen collected from a Castanopsis sieboldii forest in Mt. Tohken, Kagoshima Prefecture, Japan (KPM-NC 27968) had an identical RPB1 sequence to O. japonimontana, which was inferred to be sister to $O$. tenuipes in the $R P B 1$ tree with moderate BS support. This result was confirmed by sequencing the $R P B 1$ region of the specimen twice using different primer pairs. Furthermore, one $O$. potteri specimen from Minnesota, USA (RH1181; KPM-NC 17828) had at least two heterogeneous $R P B 1$ sequences, one of which was apparently derived from 0 . potteri but another was remarkably divergent from the other $O$. potteri sequences. The $M L$ phylogeny showed that the divergent sequence from the RH1181 specimen forms its own clade and is an unknown species-level lineage that is sister to 0 . kobayasii (Fig. 2). It should also be noted that the TEF1 sequence of a $O$. japonimontana specimen from Mts. Tanzawa, Kanagawa Prefecture (KPM-NC 27623; Fig. 4g) was remarkably divergent from the other 0 . japonimontana sequences (i.e., the TEF1 identity between the two specimens from Mts. Tanzawa [KPM-NC 27622, 27623] was 98.96\% [1051/1060 bp]) despite the high sequence homogeneity of $O$. japonimontana in the other three regions. For comparison, the TEF1 sequence identity between $O$. tenuipes (INSD acc. no.: MT874813) and O. durianelloides (MT874817) was 98.65\% (1094/1109 bp.)]

Network analysis based on the multi-locus dataset of subgenus Octaviania

The network analysis of the multi-locus dataset supported the $O$. tenuipes specimen with the RPB1 sequence of $O$. japonimontana (KPM-NC 27968; Fig. 2) in the position of an intermediate lineage between $O$. tenuipes and 0 . japonimontana, showing a high degree of reticulation in the tree (Fig. 3 ). This relationship was supported with high bootstrap values (86.8-100\%). On the other hand, no other clear reticulations suggest recent hybridization among species in subg. Octaviania.

\section{Taxonomy}

Based on our morphological studies and phylogenetic results (Fig. 1), we describe two new species, $O$. tenuipes and $O$. tomentosa, from Japan. The multi-locus phylogenetic analyses also strongly support $O$. potteri stat. nov. as sister to $O$. hesperi in $O$. subg. Octaviania (Fig. 1). Furthermore, our nLSU gene tree 
shows that $O$. potteri stat. nov. is phylogenetically distant from $O$. asterosperma var. asterosperma (Fig. $\mathrm{S} 1)$. We conclude that the taxon previously considered as $O$. asterosperma var. potteri is a distinct species from 0 . asterosperma s. str., and we propose a new status, Octaviania potteri, for the former taxon.

We are aware of the work by Kuo and Ortiz-Santana (2020) that proposed the synonymy of all the sequestrate Leccinoideae within a broadly circumscribed genus Leccinum s.l.. While the phylogenetic analyses of Kuo and Ortiz-Santana (2020) resolved monophyletic clades for all of the sequestrate genera (e.g., Octaviania, Chamonixia, Turmalinea and Rossbeevera), several other major clades of epigeous Leccinoideae taxa were otherwise poorly resolved. Based on the lack of resolution in their phylogenetic trees and the uncertainty that remains about the evolutionary relationships within the Leccinoideae, we opt to retain the sequestrate genus names Octaviania, Chamonixia, Rossbeevera and Turmalinea. We acknowledge that these sequestrate taxa belong to the Leccinoideae but feel that synonymy with Leccinum is premature, results in the loss of information, and does little to clarify the taxonomy and phylogeny of this group. In our multi-locus phylogeny, some relationships within Leccinoideae clades that were unresolved in Kuo and Ortiz-Santana (2020) were resolved with high statistical support (i.e., ML BS $\geq 75 \%$ and $\mathrm{PP} \geq 0.97$; Fig. 1). For example, phylogenetic placement of the core clade of Leccinum (= Leccinum s.str.) was not resolved in Kuo and Ortiz-Santana (2020), whereas our phylogeny supported that Leccinum s.str. was sister to the clade comprised of Leccinellum s. str., two undefined leccinoid clades, Rossbeevera and Turmalinea (Fig. 1). Our phylogeny also supported monophyly of the Leccinellum s. str. clade, which was not strongly supported in Kuo and Ortiz-Santana (2020). However, we could not include the two independent clades, Leccinum talamancae and L. longicurvipes, whose phylogenetic positions within the Leccinoideae remained uncertain. Our results suggest that we need to further address the phylogeny and systematics of Leccinoideae before lumping together all the welldefined epigeous and sequestrate genera into one large and broadly circumscribed genus. We will wait to determine a final taxonomic scheme for the sequestrate genera until a more highly resolved phylogeny becomes available that provides appropriate insight on this group.

Octaviania tenuipes Orihara, sp. nov.

MycoBank MB 836874

Figures $4 a-f$

= Octaviania sp. “E”, nom. prov., Persoonia 28: 104

Diagnosis: This species is morphologically similar to some species in Octaviania subg. Octaviania, but is distinguished by the combination of the following characteristics: soft, whitish basidiomata with a more or less developed stipe sometimes exceeding $10 \mathrm{~mm}$ long at the base; a thin peridium that is mostly less than $0.5 \mathrm{~mm}$ thick; basidiospores $9.3-(9.5-) 13.3(-15) \times(8.4-) 8.5-11.3(-11.5) \mu \mathrm{m}$ with acute pyramidal spines that have one simple cavity inside.

\section{Etymology}


referring to the slender stipe (sterile base) of the species, which is unique in the genus.

\section{Holotype}

JAPAN, Miyazaki Pref., Aya Town, under Castanopsis sieboldii, 26 Nov. 2012, leg. T. Orihara \& S. Kurogi, KPM-NC 27972.

\section{Description}

Basidiomata sequestrate, up to $21 \mathrm{~mm}$ in diam., soft, depressed-globose or reniform, surface smooth or slightly floccose, white at first, becoming dirty white to light yellowish brown at maturity, turning immediately wine red when immature specimens are touched, immediately blue when mature specimens are touched, gradually oxidizing further to black, with a more or less developed stipe that sometimes exceeds $10 \mathrm{~mm}$ long, becoming conspicuously slender at the bottom. Peridium thin, mostly less than $0.5 \mathrm{~mm}$ thick. Gleba whitish in youth, then becoming brown and finally blackish brown, somewhat watery, composed of darker-colored locules filled with basidiospores and whitish mycelial veins. Stipe (sterile base) well developed compared to other typical species of the genus, often with some subhyaline spots inside, occasionally turning red (in immature basidiomata) or blue (in mature basidiomata) when cut. Odor pleasant, sweet.

Basidiospores 9.3-(9.5-)13.3(-15) × (8.4-)8.5-11.3(-11.5) $\mu \mathrm{m}$, mean $11.3 \times 9.9 \mu \mathrm{m}$ (SD: 1.00 [length], 0.67 [width]), subglobose to broadly ellipsoid $\left(Q=1-1.42, Q_{m}=1.14\right)$, light yellowish brown to brown, covered with coarse, acute, pyramidal spines 1.1-3.3 $\mu \mathrm{m}$ high and 1-4.5 $\mu \mathrm{m}$ wide with a single, simple cavity inside, spore walls 1-1.6 $\mu \mathrm{m}$ thick. Basidia 21-32 $\times 8-14 \mu \mathrm{m}$, mean $26 \times 11.1 \mu \mathrm{m}$, clavate, hyaline, 2-, 3- or 4-spored. Hymenium present but poorly developed, comprised of basidia and basidioles. Subhymenium absent, basidia connected to branched filamentous hyphae directly extending from trama. Trama hyaline, of subparallel to loosely interwoven, non-inflated, thin-walled (up to $0.8 \mu \mathrm{m}$ ) filamentous hyphae 2-9 $\mu \mathrm{m}$ broad. Peridium thin, mostly $100-400 \mu \mathrm{m}$ and sometimes up to $650 \mu \mathrm{m}$ thick, of densely interwoven, often inflated filamentous hyphae 2-17 $\mu \mathrm{m}$ broad when immature, gradually inflated with age up to $40 \mu \mathrm{m}$ in diam., becoming pseudoparenchymatous cells at maturity, walls $0.5-1.2 \mu \mathrm{m}$ thick, outermost hyphae pigmented brown to fuscous, somewhat narrower, up to $10 \mu \mathrm{m}$ broad, but not forming a distinct layer. Stipe (sterile base) of compactly interwoven, hyaline, thin-walled, inflated hyphae 3$22 \mu \mathrm{m}$ broad, partially intermingled with large, irregular-shaped, pseudoparenchymatous cells up to $60 \mu \mathrm{m}$ in diam., walls $0.5-1.3 \mu \mathrm{m}$ thick. Clamp connections absent in all tissues.

\section{Habitat, distribution and seasonality}

hypogeous or subhypogeous under evergreen Fagaceae, widely distributed throughout Japan; spring to early summer and autumn to early winter.

Other specimens examined: JAPAN: Tokyo Met., Hachioji City, Mt. Takao, M. Nakajima, 7 Sep. 2015, KPMNC 28187; Hachijo Island, Hachijo Town, along Boh-ei Rd., under Castanopsis sieboldii, 31 Oct. 2003, H. 
Sasaki 257, KPM-NC 28191; ibid, H. Sasaki 261, KPM-NC 28192; Hachijo Island, Hachijo Town, Mitsune, Kamogawa Forestry Rd., under C. sieboldii, 15 Jul. 2015, A. Hosono, KPM-NC 27958; Hachijo Island, Hachijo Town, Mitsune, under C. sieboldii, T. Orihara, KPM-NC 26008; ibid, 29 Jun. 2003, H. Sasaki 157, KPM-NC 28190; ibid, 2 Jul. 2005, H. Sasaki 567, KPM-NC 28193; Chiba Pref., Katsuura City, Okitsu, under Lithocarpus edulis, 8 May 2016, T. Kasuya, KPM-NC 27956; Kanagawa Pref., Hakone Town, Hakoneyumoto, Soh-un Park, under C. sieboldii, 2 Oct. 2016, leg. T. Orihara, KPM-NC 27957; Odawara City, Iryuda, near Myoriki-ji Shrine, under C. sieboldii, 1 Dec. 2016, M. Nakajima, KPM-NC 25370; Miyazaki Pref., Miyazaki City, Tano-cho-otsu, Tano Forest Science Station, Miyazaki Univ., under C. cuspidata, 22 Nov. 2012, T. Orihara, KPM-NC 27960; Nichinan City, Inohae Valley, 23 Nov. 2012, T. Orihara, KPM-NC 27965; ibid, under Q. gilva and Q. salicina, KPM-NC 27964; Kagoshima Pref., Tarumizu City, Mt. Tohken, under $C$. sieboldii, 24 Nov. 2012, T. Orihara, KPM-NC 27968; Kimotsuki-gun Minamiosumi Town (the former Sata Town), Nishikata, under C. sieboldii, 30 Nov. 2003, H. Sasaki 306, KPM-NC 28405; ibid, H. Sasaki 308, KPM-NC 28406; ibid, H. Sasaki 309, KPM-NC 28407; ibid, H. Sasaki 310, KPM-NC 28408; ibid, H. Sasaki 311, KPM-NC 28409; ibid, H. Sasaki 312, KPM-NC 28410; Kimotsuki-gun Minamiosumi Town (the former Sata Town), near Kaitaku-iriguchi bus stop, under C. sieboldii and Q. glauca, H. Sasaki 317, KPM-NC 28411; Tanegashima Isl., Nishino-omote City, Anjoh, Ohno Forestry Rd., along Ohkawada River, under $C$. sieboldii, 8 Dec. 2015, T. Orihara, KPM-NC 24889; Nishino-omote City, Furuta under Lithocarpus edulis, 28 Nov. 2003, H. Sasaki 301, KPM-NC 28404; ibid, under C. sieboldii, 8 Dec. 2015, T. Orihara, KPM-NC 24891; Tanegashima Isl., Minamitane Town, Nakanoshita, near Shimonakahachiman Shrine, under Castanopsis sieboldii, Quercus phillyraeoides and Lithocarpus edulis, 28 Nov. 2003, H. Sasaki 294, KPM-NC 28401; ibid, H. Sasaki 295, KPM-NC 28402; Tanegashima Isl., Nakatane Town, Masuda, near Tanegashima Airport, 28 Nov. 2003, H. Sasaki 298, KPM-NC 28403; Amami-oshima Isl., Yamato-son, north-eastern foot of Mt Yuwan, umder C. sieboldii subsp. lutchuensis, 17 Nov. 2007, T. Orihara, KPM-NC 17813.

\section{Remarks}

Orihara et al. (2012a) tentatively described O. tenuipes as "Octaviania sp. E" because, at that time only one collection of an immature basidioma had been examined and the morphology of this new species was not sufficiently known. This species has now been recorded from subtropical to temperate regions in Japan, associated with Castanopsis and evergreen Quercus tree species. Morphologically, O. tenuipes tends to have a rather slender and well-developed stipe compared to the other species of Octaviania. Octaviania japonimontana, which is phylogenetically close to 0 . tenuipes, is somewhat similar morphologically, but O. japonimontana occurs in deciduous Fagaceae forests (with Q. crispula and Fagus spp.) and tends to have basidiomata with thicker peridia and a more rubbery texture. However, these differences are sometimes inconspicuous so molecular methods are sometimes necessary to confirm the species identification. Another closely related species, 0 . durianelloides Orihara, also resembles 0 . tenuipes when the basidiomata are immature. However, at maturity the basidiomata of 0 . durianelloides have conspicuous brown scales or warts on the surface, which is unique in the genus.

Octaviania tomentosa Orihara, sp. nov. 
Figure 5

Diagnosis: This species is distinguished from other Octaviania species in the combination of the following characteristics: small, soft, felty to tomentose, white to dirty white basidiomata up to $15 \mathrm{~mm}$ in diam.; peridium usually very thin (mostly 70-250 $\mu \mathrm{m}$ thick), composed of filamentous hyphae and isodiametric cells with thin cell-walls (up to $0.8 \mu \mathrm{m}$ thick); Basidiospores $10.2-(11-) 14.4(-15) \times 8.6-$ (8.8-)12.6(-13.2) $\mu \mathrm{m}$, with acute or sometimes curled, pyramidal spines that have a few slit-like cavities inside.

\section{Etymology}

Latin, tomentosa (felty or cottony), referring to the tomentose surface of the basidiomata.

Holotype: JAPAN: Ibaraki Pref., Kasama City, Mt. Sashiro, under Q. myrsinifolia, 9 Sep. 2018, M. Ohmae \& T. Orihara, KPM-NC 27954.

\section{Description}

Basidiomata sequestrate, up to $15 \mathrm{~mm}$ in diam., soft, subglobose, depressed-globose or reniform, surface felty to tomentose, white to dirty white, not becoming yellowish or brownish with age, turning blue or bright red when touched or injured, immature basidiomata tending to turn red rather than blue where touched, after exposure gradually turning black, stipe short, not exceeding $3 \mathrm{~mm}$ long, with white rhizomorphs. Peridium usually very thin (less than $0.25 \mathrm{~mm}$ ) but sometimes variable in thickness, in some cases up to $0.4 \mathrm{~mm}$, context white, showing the same pattern of discoloration as the peridial surface. Gleba beige in youth, becoming brown at maturity, somewhat watery, particularly in young basidiomata, composed of locules filled with yellowish brown to brown basidiospores and whitish mycelial veins, typical of the genus. Stipe (sterile base) context white, sometimes with some subhyaline spots inside. Odor sweet at maturity.

Basidiospores 10.2-(11-)14.4(-15) × 8.6-(8.8-)12.6(-13.2) $\mu \mathrm{m}$, mean 12.3 × $10.6 \mu \mathrm{m}$ (SD: 1.01 [length], 0.96 [width]), subglobose to broadly ellipsoid $\left(Q=1.04-1.34, Q_{m}=1.16\right)$, light yellowish brown to ochraceous brown, covered with coarse, acute, sometimes curled, large pyramidal spines 1.6-3.3 $\mu \mathrm{m}$ high and 1.5-4.8 $\mu \mathrm{m}$ wide with a few slit-like cavities inside, spore walls $1.3-3 \mu \mathrm{m}$ thick, with a long pedicel 6-15.5 × 1.5-2.2 $\mu \mathrm{m}$ at the base. Basidia 26-39 ×9-14 $\mathrm{mm}$, mean 32.1 × $11.1 \mu \mathrm{m}$, clavate, colorless, 4-, 2- or more rarely 3-spored. Subhymenium not well developed. Basidia and basidioles randomly extending from hyphae in tramal plates. Tramal plates 15-80 $\mu \mathrm{m}$ thick, of parallel, colorless, thin-walled (up to $0.6 \mu \mathrm{m}$ ) filamentous hyphae $2.5-7 \mu \mathrm{m}$ broad. Peridium usually $70-250 \mu \mathrm{m}$ thick, context up to $180 \mu \mathrm{m}$ thick, colorless, of interwoven, septate, thin-walled (up to $0.6 \mu \mathrm{m}$ ) filamentous hyphae approximately 3-8 $\mu \mathrm{m}$ broad when immature, cells becoming swollen and isodiametric (up to $25 \mu \mathrm{m}$ in diam.) so that peridial tissue is pseudoparenchyma by maturity, the mature cell walls up to 
$0.8 \mu \mathrm{m}$ thick; peridiopellis thin, up to $100 \mu \mathrm{m}$ across, pigmented yellow-brown, surface turf-like but fragile and easily crushed, of interwoven filamentous hyphae or inflated cells almost the same size as those of inner context (up to $25 \mu \mathrm{m}$ in diam.). Stipe (sterile base) of compact, interwoven, partially isodiametric, thin-walled (up to $0.8 \mu \mathrm{m}$ ), hyaline hyphae $4-20 \mu \mathrm{m}$ broad. Clamp connections absent in all tissues.

\section{Habitat, distribution and seasonality}

hypogeous or subhypogeous under evergreen Fagaceae, found on Amami-oshima Island in the Ryukyu island chain and in eastern Honshu (Kanto region), Japan; summer to autumn.

Specimens examined: JAPAN: Kanagawa Prefecture, Minami-ashigara City, Uchiyama, under Quercus myrsinifolia, 4 July 2016, T. Orihara, KPM-NC 27945; ibid, 3 Sep. 2017, T. Orihara, KPM-NC 27955; ibid, 24 Sep. 2018, T. Orihara, KPM-NC 27946; ibid, 19 Jul. 2020, Y. Kaneko \& T. Orihara, KPM-NC 28415; Ibaraki Pref., Kasama City, Mt. Sashiro, under Q. myrsinifolia, 22 Jul. 2017, M. Ohmae, KPM-NC 27953; Tochigi Pref., Sano City, Mt. Karasawa, under Castanopsis sieboldii, 24 Jul. 2016, M. Ohmae, KPM-NC 27952; ibid, 20 Jul. 2018, M. Ohmae, KPM-NC 27947; Shizuoka Pref., Suntoh District, Oyama Town, Ashigara Pass, 12 Jul. 2020, Y. Kaneko, KPM-NC 28416; ibid, 19 Jul. 2020, Y. Kaneko, KPM-NC 28412; ibid, Y. Kaneko \& T. Orihara, KPM-NC 28413; ibid, Y. Kaneko, KPM-NC 28414; Kagoshima Pref., Amami-oshima Isl., Uken-son, Yuwan, umder C. sieboldii subsp. lutchuensis, 29 Jun. 2014, T. Orihara, KPM-NC 23934.

\section{Remarks}

This rare species has only been found from four sites in and around the Kanto region in Honshu and from one site in Amami-oshima Island in the Ryukyu island chain despite extensive long-term collecting of Octaviania spp. throughout Japan. These two disjunct areas are about $1200 \mathrm{~km}$ apart and the climates and vegetation are also quite different between the two areas (temperate evergreen forests on mainland Japan vs. subtropical forests in the Ryukyu Islands). The multi-locus tree (Fig. 1) as well as the singlegene trees (Fig. 2) clearly show generic divergence between the two disjunct lineages. The specimen from Amami-oshima Island had a thicker peridium than the specimens from the Kanto region (ca. 150-400 $\mu \mathrm{m}$ thick in the Amami-oshima specimen vs. 70-250 um thick in specimens from Kanto). However, we treat these two lineages as infraspecific variations because of the lesser degree of genetic divergence compared to other species-level divergence in both the species tree and individual gene trees (Figs. 1-2). For instance, the sequence similarity of $\mathrm{nLSU}$ between the Amami-oshima specimen and the holotype from Honshu is $99.15 \%$ (935 bp / $943 \mathrm{bp}$ ), whereas the nLSU similarity between holotypes of $O$. yaeyamaensis and 0 . etchuensis, which are genetically the least divergent species within subgenus Octaviania, is $98.31 \%$ ( $875 \mathrm{bp} / 890 \mathrm{bp}$ ). In addition, we cannot infer the potential mating incompatibility between these geographically isolated, but unculturable specimens.

Octaviania tomentosa morphologically resembles $O$. hesperi in the relatively small, whitish basidiomata. However, $O$. hesperi is distinguished from $O$. tomentosa by its slightly larger basidiospores with lower $Q$ values $(10-15.6(-18.2) \times 9.4-(9.9-) 14.8(-17.8) \mu \mathrm{m}$, mean $12.8 \times 12.1 \mu \mathrm{m} ; Q=0.96-1.15)$. Octaviania hesperi also has larger pyramidal spore ornamentation $(2-(2.1-) 3.6(-4) \times 1.3-(1.7-) 5.4(-5.7) \mu \mathrm{m})$ with 
irregularly shaped, multiple slits inside (Orihara et al. 2012a). The felty to tomentose surface of the $O$. tomentosa basidiomata is also a distinguishing character that is absent among any of the phylogenetically related species in 0 . subg. Octaviania.

Octaviania potteri (Singer \& A.H. Sm.) Orihara, Healy, M.E. Sm., stat. nov.

MycoBank MB 836876

Figure 6

三 Octaviania asterosperma var. potteri Singer \& A.H. Sm., Memoirs of the Torrey Botanical Club 21 (3): 10 (1959) [MB 353662]

Holotype: USA: Michigan, Ithaca, Gratiot, Schovence's Woods on exposed soil along a logging road in rich heavy soil (mud), 17 Sep. 1949, V. Potter 8898, MICH 12376.

\section{Description}

Basidiomata sequestrate, mostly 8-20 mm in diam., firm, rubbery, subglobose, depressed-globose or reniform, surface smooth or floccose to minutely scaly, white at first then becoming ochraceous at maturity, initially turning red or sometimes greenish blue at the base when touched or injured, gradually turning black, stipe reduced or rudimentary, with white rhizomorphs at the base. Peridium varying in thickness, but mostly not exceeding $0.8 \mathrm{~mm}$ thick, context white, showing the same pattern of discoloration as the peridial surface. Gleba brown at maturity, finally becoming blackish brown, composed of locules filled with brown basidiospores and whitish mycelial veins, typical of the genus. Stipe (sterile base) rudimentary to pulvinate, white. Odor sweet to cloyingly sweet at maturity. Taste not recorded.

Basidiospores 9-13.4(-14) × 7.6-12.3(-13.2) $\mu \mathrm{m}$, mean 11.2 ×9.9 $\mu \mathrm{m}$ (SD: 1.06 [length], 1.14 [width]), subglobose to broadly ellipsoid $\left(Q=1-1.42, Q_{m}=1.13\right)$, dextrinoid, light yellowish brown to ochraceous brown, covered with coarse, large pyramidal spines 1.6-3.4 $\mu \mathrm{m}$ high and 1.6-4.5 $\mu \mathrm{m}$ wide with a single slit-like cavity inside, spore walls 1.4-2.2 $\mu \mathrm{m}$ thick, with a pedicel up to $13 \mu \mathrm{m}$ long at the base. Basidia 19-35 $\times 10-15.5 \mu \mathrm{m}$, clavate, mostly 2-spored or rarely 3- or 4-spored. Subhymenium not well developed.

Tramal plates 30-200 $\mu \mathrm{m}$ thick, hyaline or light yellowish brown, of subparallel to interwoven, inflated, hyaline, filamentous hyphae 3-15 $\mu \mathrm{m}$ broad. Peridium 200-450 $\mu \mathrm{m}$ thick, context hyaline or light yellowish brown, pigmented yellow-brown near surface, of interwoven, inflated filamentous hyphae 3$13 \mu \mathrm{m}$ broad, pseudoparenchymatous cells up to $45 \mu \mathrm{m}$ in diam. at maturity, cell walls ca. $1 \mu \mathrm{m}$ thick; peridiopellis very thin (up to $60 \mu \mathrm{m}$ thick) or absent in some parts, of partially inflated, septate, filamentous hyphae 3-7 $\mu \mathrm{m}$ broad subparallel to surface. Clamp connections absent in all tissues.

\section{Habitat, known distribution and seasonality}


hypogeous or subhypogeous under species of Fagaceae, eastern North America (Canada [Quebec], USA [IA, IN, FL, MN, NC, WV]), East Asia (Japan [Hokkaido]), South America (Colombia); summer to autumn.

Other specimens examined: UNITED STATES OF AMERICA: Iowa, Boone Co., Ledges State Park, under Quercus alba, 20 Sep. 2007, R. Healy RH3, FH 00284316; Emmet Co., Fort Defiance State Park, under Quercus rubra, Ostrya virginiana, Tilia americana, 26 Jul. 2000. R. Healy RH720, ISC-F-0072478; Story Co., Ames, Inis Grove Park, under Q. alba, O. virginiana, T. americana, 18 Aug.1998, R. Healy RH234, ISC-F0072476; Ames, YMCA Woods, under Q. alba, 21 Sep. 1996, R. Healy, ISC-F-0072477; ibid, 25 Jul. 1997, $R$. Healy RH48 (ISC-F-0072479); ibid, 25 Aug. 1999, R. Healy RH555 (ISC-F-0072471); ibid, 9 Aug. 2000, $R$. Healy RH750, ISC-F-0072473; ibid, 27 Aug. 2000, R. Healy RH782, ISC-F-0072475; ibid, 27 Aug, 2007, R. Healy, FLAS-F-62023; ibid, 25 Sep. 2006, E. Braun and Mycology Class, ISC-F-0072472; ibid, 6 Sep. 2007, R. Healy RH30, FH 00284311 (duplicate: KPM-NC 17827 \& FLAS-F-66562); Hickory Grove Park, under Quercus macrocarpa and T. americana, on slope by man-made lake, 11 Aug. 2009, R. Healy, FLAS-F62022; Van Buren Co., Lacey-Keosaqua State Park, under Q. alba and T. americana, 30 Jul. 2001, L. McCormick, ISC-F-0072474; Indiana, Fort Wayne, 7 Nov. 2014, K. Parker (MES806), FLAS-F-66547; ibid, K. Parker (MES807), FLAS-F-66548; Minnesota, Fillmore Co., Forestville State Park, in mixed oak woods, 5 Aug. 2009, E.G. McLaughlin RH973, MIN 912630; ibid, 10 Jul. 2010, R. Healy RH1181, KPM-NC 17828 (duplicate: FLAS-F-66563); Rice Co., Nerstrand Big Woods State Park, in mixed oak woods, 8 Aug. 2009, $R$. Estell RH997, MIN 912622; Washington Co., Afton State Park, in mixed oak woods, 27 Aug. 2009, R. Healy RH1017, MIN912618; ibid, D.L. McLaughlin RH1018, MIN912635; North Carolina, McDowell Co., along Blue Ridge Parkway near Mineral Museum, 21 Sep. 2003, T. Eliott (Trappe 32742), FLAS-F-66549; at junction of Jones and Onslow Co., Croatan National Forest, White Oak River, 17 Jul. 2007, T. Eliott (MES801), FLAS-F-66550; Florida, Wakulla Co., Skipper Bay road, St Marks NW refuge, under Pinus elliottii and Q. virginiana, 29 Dec. 2003, D. Mitchell \& W. Roody DMEL04-18 (Trappe 32178), OSC 131925; West Virginia, Randolph Co., Stuarts Park, 19 Sep. 1999, K. St. Louis (Trappe 25908), FLAS-F-66551; McDowell Co., Bervind Wildlife Management Area, 11 Jul. 2002, D. Mitchell (Trappe 27950), FLAS-F-66773; CANADA: Quebec, Montreal, 13 Sep. 1991, F. Marzitelli (Trappe 12445), FLAS-F-66546; JAPAN: Hokkaido, Tomakomai City, near Kuchinashi-numa Pond, under Quercus crispula, 12 Sep. 2011a, M. Ohmae, KPMNC 18032; ibid, 21 Sep. 2012, K. Yamamoto \& T. Orihara, KPM-NC 25043; COLOMBIA: Cundinamarca Province, Guacheta, Reserva Natural el Chaute o Robledal, Road from Guacheta to Raquira km 6, under Quercus humboldtii, 28 Feb. 2020, A. Corrales 1036, HUA 222100.

Remarks: Octaviania potteri was originally described based on a specimen from Michigan, USA (Singer and Smith 1960). The North American specimens have been reported from Quebec province in Eastern Canada and six states in eastern North America (NA). However this taxon has never been collected from western NA despite active ongoing searches for truffles in California and the Pacific Northwest (e.g. Gilkey 1954, Trappe and Castellano 2000, Trappe et al. 2009). Interestingly, this species shows a remarkable disjunct distribution between eastern North America, South America (Colombia) and East Asia (Japan) (Fig. 1). This is the broadest distributional range of any known Octaviania species. As far as we know, this is also the first record of Octaviania sensu stricto from South America. The mechanism of dispersal of $O$. potteri individuals is worth being investigated from a phylogeographical viewpoint in the 
future. Morphologically, it is difficult to characterize this species because most characters of the basidiomata are typical of other taxa in the subgenus Octaviania. However, the distinctive dextrinoid reaction of the basidiospores and the very thin peridiopellis (i.e., an outermost filamentous layer of the peridium) that is sometimes absent in patches are two features that are distinct compared to any of the closely related species.

\section{Discussion}

Europe was considered the center of biodiversity of the genus Octaviania since the first description in 1831 (e.g., Hesse 1891; Pegler \& Young 1979; Vittadini 1831) but Orihara et al. (2012a) revealed that this genus is also remarkably diverse in East Asia. Orihara et al. (2012a) also described 11 new species and one species that they provisionally named as "Octaviania sp. E". Our study reinforces the high species diversity of Octaviania in East Asia by proposing two additional new species, 0 . tenuipes (= "Octaviania sp. $E^{\prime \prime}$ ) and $O$. tomentosa. Our studies also revealed the new status of $O$. potteri, which was previously known only from eastern North America (Singer \& Smith 1960) and is shown here to also occur in East Asia (Japan) and in South America (Colombia). Taking these new results into account, approximately half of the known species of Octaviania can be found in Japan (i.e., 14 species). In contrast, only four species are known from North America (Coker and Couch 1928; Orihara et al. 2012a; Singer and Smith 1960; Trappe and Castellano 2000) and approximately six species are currently recognized from Europe (Paz et al. 2016). These results suggest that Japan and the other regions of temperate East Asia are likely the center of diversity for the genus Octaviania.

Notably, we also found that the distribution of 0 . potteri extends to a montane dry forest in Colombia dominated by the ectomycorrhizal host tree Quercus humboldtii. This is the first record of a true Octaviania from South America. Horak (1964) described Octaviania chilensis Horak from Chile, but this species was later transferred to Stephanospora Pat. in the Agaricales (Vidal 2004). Species of Octaviania subg. Octaviania are always associated with Fagaceae trees, and Colombian Q. humboldtii is considered to have migrated from Central America via the Isthmus of Panama in the Middle to Late Pleistocene (van der Hammen 1974). Thus, it is most likely that $O$. potteri migrated from North and Central America along with $Q$. humboldtii, the only oak species that is native to South America.

Generic relationships in the Leccinoideae, particularly among the genera Leccinum, Leccinellum, Chamonixia, Octaviania, Rossbeevera and Turmalinea, have never been fully resolved with confidence in previous phylogenetic and systematic studies (e.g., Kuo and Ortiz-Santana 2020; Orihara et al. 2012a, 2016a; Wu et al. 2014, 2016). Orihara et al. (2016a) conducted phylogenetic analyses based on three nuclear loci (i.e., ITS, nLSU and TEF1), but only the sister relationship between Rossbeevera and Turmalinea was resolved with strong statistical support (PP $\geq 0.98$ and $M L B S \geq 70 \%$ ). Kuo and OrtizSantana (2020) provided a large-scale, multi-locus phylogeny that focused on epigeous Leccinum and Leccinellum species based on the $\mathrm{nLSU}, T E F 1$ and RPB2 regions. The resulting phylogenetic tree showed many polyphyletic clades of Leccinum and Leccinellum s.I. within Leccinoideae and most of their phylogenetic relationships were unresolved. Accordingly, Kuo and Ortiz-Santana (2020) treated all the 
epigeous bolete and hypogeous sequestrate taxa in Leccinoideae as a broadly circumscribed genus Leccinum s.I.. In our study, we incorporated the RPB1 region as well as ITS, nLSU and TEF1 into our multilocus dataset. The resulting trees provided robust phylogenetic support for most of the generic relationships in the Leccinoideae. The two exceptions were the lack of resolution in the branching pattern between Chamonixia and the other genera as well as the phylogenetic placement of some generic-level clades of epigeous Leccinoideae excluded from Leccinum and Leccinellum s.str. (i.e., Leccinellum albellum, L. quercophilum and Leccinum violaceotinctum; Fig. 1). This multi-locus phylogeny also resolved most of the species-level relationships in Octaviania. This exemplifies the usefulness of RPB1 for phylogenetic studies on Leccinoideae and highlights the fact that our multi-locus phylogeny shows promise for resolving the genus-level relationships within the Leccinoideae in the near future.

Interestingly, we found that some of the Octaviania specimens had heterogeneous RPB1 sequences compared to the other specimens of the same species. Comparison of the four single-gene tree topologies unexpectedly revealed that one $O$. tenuipes specimen (KPM-NC 27968) had an RPB1 sequence identical to 0 . japonimontana (Fig. 2). Furthermore, the RPB1 phylogeny showed that one $O$. potteri specimen from Minnesota (KPM-NC 17828; RH1181) was not placed within any of the known specieslevel clades in $O$. subgenus Octaviania. Instead this specimen formed a unique branch that was distant from any species-level clades in the subgenus (Fig. 2). These topological inconsistencies would be most reasonably explained by interspecific hybridization between two closely related species.

Octaviania tenuipes consistently occurs in evergreen Quercus and Castanopsis forests in subtropical to temperate regions of Japan, whereas 0 . japonimontana occurs in deciduous Quercus and Fagus crenata forests in mountainous, temperate regions. The possible "hybrid" specimen between $O$. tenuipes and $O$. japonimontana (KPM-NC 27968) was collected in the Takakuma mountain range of Kyushu, Japan, which is known as a southern border of the distribution of $F$. crenata, the potential ectomycorrhizal host of $O$. japonimontana. Although we have not been able to find $O$. japonimontana in that mountain range, it is possible that the two closely related species incidentally inhabited the two adjacent vegetations and hybridized due to minimal putative reproductive barriers between the two species. This potential interspecific hybridization likely occurred very recently because the "hybrid" 0 . tenuipes specimen (KPMNC 27968) has a conserved RPB1 sequence of $O$. japonimontana (i.e., $100 \%$ identical to the other $O$. japonimontana sequences). The hybrid nature of this specimen was also supported by the network analysis based on the combined dataset of the ITS, $\mathrm{nLSU}, R P B 1$ and TEF1 regions (Fig. 3). Stukenbrock (2016) summarized that when two allopatric, fungal species come into contact by chance they more readily hybridized than sympatric species, referring to the case of Neurospora species (Turner et al. 2011). Leducq et al. (2016) clarified that one North American lineage in Saccharomyces paradoxus is an incipient, hybrid species resulting from secondary contact of two geographically isolated, allopatric lineages after the last glaciation. Similarly, Gladieux et al. (2011) showed that hybridization between two closely related European Microbotryum species tends to be induced by secondary contact following initial divergence in allopatry. Although genome-level genetic comparisons will be needed to verify a potential hybridization between $O$. tenuipes and $O$. japonimontana, our hypothesis of hybridization is supported by other cases of hybridization in fungi such as those discussed above. 
Similarly, the heterogenous RPB1 sequence in the 0 . potteri specimen from Minnesota (KPM-NC 17828 $[R H 1181])$ is the result of another interspecific hybridization between 0 . potteri and an unknown North American species within subgenus Octaviania. So far, no such species closely related to 0 . kobayasii has been described, but our results strongly suggest that there is another undescribed species in this lineage from North America. We assume that this unknown Octaviania sp. is sympatric with 0 . potteri or at least they have bordering distributions somewhere in the upper Midwest of eastern North America. Further collecting surveys for truffle-like fungi in this region may confirm the existence of this unknown Octaviania species in the future.

In addition, the distinct intraspecific divergence between the 0 . japonimontana KPM-NC 26723 specimen and the other specimens in the TEF1 phylogeny could be an additional signature of past intraspecific hybridization (Figs. 2 and $4 \mathrm{~g}$ ). This topological pattern is similar to that of 0 . potteri in the RPB1 phylogeny, although the genetic distance between the two lineages is less in the case of $O$. japonimontana. Therefore, it is likely that an unknown intraspecific lineage genetically distant to the core O. japonimontana clade exists or existed in the recent past around the habitat of the KPM-NC 26723 specimen. Another possible cause of the topological differences is unusually accelerated molecular evolution of the KPM-NC 26723 specimen, but no such clear divergence was recognized in the other three DNA regions and the rate of divergence in the TEF1 tree seems stable in other species-level clades (Fig. 2). Therefore, accelerated evolutionary rates seems less likely than hybridization. Geographically, the site where this specimen was collected was only about $250 \mathrm{~m}$ away from where another $O$. japonimontana specimen (KPM-NC 26723) was collected on the same day, and we did not find any clear morphological differences between these specimens. We will refrain from assigning a new taxonomic status of this intraspecific lineage until specimens that do not show any trace of recent hybridization are collected.

Intra- and inter-specific hybridization in fungi has been frequently documented in plant pathogens (e.g., Brasier 1999; Depotter et al. 2016; Feurtey et al. 2019; Schardl and Craven 2003; Stukenbrock 2016), yeasts (e.g., Gostinčar et al. 2018; Kuehne et al. 2007; Leducq et al. 2016; Marcet-Houben and Gabaldón 2015) and morels (Morchella spp.) (Du et al. 2016, 2019, 2020) but has been rarely reported in mushroom-forming basidiomycetes (Anderson et al. 1980; Stenlid and Karlsson 1991). Orihara et al. (2016a) illustrated that the frequent topological incongruences among gene trees of the sequestrate bolete genus, Rossbeevera, which is closely related to Octaviania, were likely to be derived from intraspecific gene introgression as well as incomplete lineage sorting (ILS). As far as we know, however, the present study is the first case that demonstrated interspecific hybridization in sequestrate basidiomycetes based on molecular evidence. Given the multiple traces of introgression among intraspecific lineages shown by Orihara et al. (2016a) and the interspecific hybridization within Octaviania discussed here, it appears that the sequestrate genera in the Leccinoideae may be less reproductively isolated when the two lineages have been ecologically isolated (e.g. there is therefore no need for reproductive isolation to reinforce species boundaries). So far, the precise mechanism of these interspecific hybridizations has not been discovered and the ploidy of putative hybrid specimens should be examined based on genome-level comparisons and analyses of chromosomes. We nevertheless 
suppose that interspecific hybridization may have promoted high genetic diversity within the sequestrate genera of the subfamily Leccinoideae.

\section{Conclusion}

The multi-locus phylogeny comprised of ITS and LSU nrDNA, TEF1 and RPB1 sequences provided a robust phylogenetic framework of our study and revealed the phylogenetic placement of two new Octaviania species, $\boldsymbol{O}$. tenuipes and $\boldsymbol{O}$. tomentosa collected from Japan. In addition to the phylogenetic analyses, critical morphological examination based on recently collected North American specimens and the holotype concluded that $O$. asterosperma var. potteri should be treated as an independent species, $O$. potteri stat. nov. Interestingly, O. potteri exhibited an unusually broad range of distribution (i.e., North America, Japan and Colombia), and this is the first record of Octaviania from South America. Comparison of the four single-gene tree topologies revealed that one 0 . tenuipes specimen had an RPB1 sequence identical to $O$. japonimontana, and one $O$. potteri specimen from Minnesota had heterogenous $R P B 1$ sequences, one of which was proved to be that of an unknown species of $O$. subg. Octaviania. The comparison also showed that one $O$. japonimontana specimen had remarkably divergent TEF1 sequence from the other 0 . japonimontana specimens. Based on these results and potential phylogeography of these species, we consider that these topological inconsistencies are due to inter- and intra-specific hybridization between two phylogenetically closely related lineages. Thus, the high genetic and species diversity of Octaviania may partly be due to frequent inter- and intra-specific hybridization. Further genomic comparison among closely related species and precise population genetics will enlighten the speciation and diversification mechanisms within Octaviania and other sequestrate genera in the Leccinoideae.

\section{Abbreviations}

ITS: Nuc rDNA internal transcribed spacer region; nLSU:Nuc rDNA large subunit (28S) region; TEF1:translation elongation factor 1-a gene; RPB1:the largest subunit of RNA polymerase II gene; INSD:the International Nucleotide Sequence Databases.

\section{Declarations}

\section{Acknowledgement}

We sincerely appreciate Michael A. Castellano, Shuichi Kurogi, Yumiko Ohba, Joseph W. Spatafora, Kohei Yamamoto, Hiroaki Yamashita and Tatiana Sanjuan for supporting our field trip or facilitating our access to herbarium specimens. We also thank to Redge Estell, Yoshinori Kaneko, Taiga Kasuya, Minoru Nakajima, Laura McCormick, David and Esther Mclaughlin, Muneyuki Ohmae, Hiromi Sasaki, Hikaru and Hitomi Yamashita for providing us valuable specimens used for this study. We thank Patricia Rogers for her assistance with a loan of the holotype of Octaviania asterosperma var. potteri from $\mathrm{MICH}$. Collecting in Colombia was done under the ANLA permit 0530 de 2014. 


\section{Authors' contributions}

Takamichi Orihara designed the study, implemented the molecular analyses and wrote the manuscript of this paper with supports by Matthew E. Smith and Rosanne Healy. Rosanne Healy collected O. potteri specimens from NA and examined holotype of the species, and took part in the molecular work. Adriana Corrales collected the $O$. potteri specimen from Colombia and provided its data to the study. Matthew $\mathrm{E}$. Smith helped to obtain a loan of the 0 . potteri holotype, designed the fieldtrip to Colombia, contributed molecular data for North American specimens of 0 . potteri and thoroughly edited the manuscript.

\section{Funding}

This study was financially supported by JSPS KAKENHI Grant-in-Aid for Young Scientists (B) (nos. 17K15184 and 25840149) and the Grant-in-Aid from Institute for Fermentation, Osaka (IFO). Matthew Smith's participation in this work was supported in part by the University of Florida's Institute for Food and Agricultural Sciences (IFAS) and by the NIFA-USDA award FLA-PLP-005289 and McIntire-Stennis project 1011527. Rosanne Healy's participation was supported in part by an award from the lowa Academy of Sciences, grants from the lowa Department of Natural Resources, and The Minnesota Department of Natural Resources, and IFAS.

\section{Availability of data and materials}

Nucleotide sequences generated for this study were deposited in INSD via NCBI GenBank website (Table 1). The full alignments of datasets for phylogenetic analyses were submitted to TreeBASE and they are available under the following URL: http://purl.org/phylo/treebase/phylows/study/TB2:S26821.

\section{Ethics approval and consent to participate}

Not applicable

\section{Adherence to national and international regulations}

All the experiments and surveys undertaken in this study comply with the current laws of the country where they were performed. The authors declare that they have no conflict with Nagoya Protocol compliances.

\section{Consent for publication}

Not applicable

\section{Competing interests}

The authors declare no conflicts of interest.

\section{References}


1. Anderson JB, Korhonen K, Ullrich RC (1980) Relationships between European and North American biological species of Armillaria mellea. Exp Mycol 4:87-95

2. Brasier CM, Cook DEL, Duncan JM (1999) Origin of a new Phytophthora pathogen through interspecific hybridization. Proc Natl Acad Sci USA 96:5878-5883. doi:10.1073/pnas.96.10.5878

3. Castellano MA, Elliott TF, Truong C, Séné O, Dentinger BTM, Henkel TW (2016) Kombocles bakaiana gen. sp. nov. (Boletaceae), a new sequestrate fungus from Cameroon. IMA Fungus 7:239-245. doi:10.5598/imafungus.2016.07.02.03

4. Castresana J (2000) Selection of conserved blocks from multiple alignments for their use in phylogenetic analysis. Mol Biol Evol 17:540-552

5. Coker WC, Couch JN (1928) The Gasteromycetes of the Eastern United States and Canada. University of North Carolina Press, Chapel Hill, North Carolina

6. Darriba D, Taboada GL, Doallo R, Posada D (2012) jModelTest 2: more models, new heuristics and parallel computing. Nat Methods 9:772. doi:10.1038/nmeth.2109

7. Depotter JRL, Seidl MF, Wood TA, Thomma BPHJ (2016) Interspecific hybridization impacts host range and pathogenicity of filamentous microbes. Curr Opin Microbiol 32:7-13. doi:10.1016/j.mib.2016.04.005

8. Desjardin DE, Wilson AW, Binder M (2008) Durianella, a new gasteroid genus of boletes from Malaysia. Mycologia 100:956-961. doi:10.3852/08-062

9. Desjardin DE, Binder M, Roekring S, Flegel T (2009) Spongiforma, a new genus of gasteroid boletes from Thailand. Fungal Divers 37:1-8

10. Dress AWM, Huson DH (2004) Constructing splits graphs. IEEE/ACM Transactions in Computational Biology Bioinformatics 1:109-115. doi:10.1109/TCBB.2004.27

11. Du XH, Wang HC, Sun JJ, Xiong LY, Yu JJ (2019) Hybridization, characterization and transferability of SSRs in the genus Morchella. Fungal Biology 123:528-538. doi:10.1016/j.funbio.2019.05.005

12. Du XH, Wu DM, Kang H, Wang H, Xu N, Li T, Chen K (2020) Heterothallism and potential hybridization events inferred for twenty-two yellow morel species. IMA Fungus 11:4. doi:10.1186/s43008-0200027-1

13. Du XH, Zhao Q, Xu J, Yang ZL (2016) High inbreeding, limited recombination and divergent evolutionary patterns between two sympatric morel species in China. Sci Rep 6:22434. doi:10.1038/srep22434

14. Feurtey A, Stevens DM, Stephan W, Stukenbrock EH (2019) Interspecific Gene Exchange Introduces High Genetic Variability in Crop Pathogen. Genome Biology Evolution 11:3095-3105. doi:10.1093/gbe/evz224

15. Galtier N, Gouy M, Gautier C (1996) SEAVIEW and PHYLO_WIN: Two graphic tools for sequence alignment and molecular phylogeny. Comput Appl Biosci 12:543-548

16. Geyer CJ (1991) Markov chain Monte Carlo maximum likelihood. In: Keramidas EM (ed) Computing science and statistics. Proceedings of the 2third Symposium on the Interface. Interface Foundation, 
Fairfax, VA, pp 156-163

17. Gilkey HM (1954) Tuberales. North American Flora Series 2. 1:1-36

18. Gladieux P, Vercken E, Fontaine MC, Hood ME, Jonot O, Couloux A, Giraud T (2011) Maintenance of fungal pathogen species that are specialized to different hosts: allopatric divergence and introgression through secondary contact. Mol Biol Evol 28:459-471. doi:10.1093/molbev/msq235. Epub 2010 Sep 13

19. Gostinčar C, Stajich JE, Zupančič J, Zalar P, Gunde-Cimerman N (2018) Genomic evidence for intraspecific hybridization in a clonal and extremely halotolerant yeast. BMC Genom 19:364. doi:10.1186/s12864-018-4751-5

20. Gouy M, Guindon S, Gascuel O (2010) SeaView version 4: a multiplatform graphical user interface for sequence alignment and phylogenetic tree building. Mol Biol Evol 27:221-224. doi:10.1093/molbev/msp259

21. Guindon S, Gascuel O (2003) A Simple, Fast, and Accurate Algorithm to Estimate Large Phylogenies by Maximum Likelihood. Syst Biol 52:696-704

22. Hall TA (1999) BioEdit: a user-friendly biological sequence alignment editor and analysis program for Windows 96/98/NT. Nucleic Acids Symposium Series 41:95-98

23. Henkel TW, Obase K, Husbands D, Uehling JK, Bonito G, Aime MC, Smith ME (2016) New Boletaceae taxa from Guyana: Binderoboletus segoi gen. and sp. nov.

24. Guyanaporus albipodus gen. and sp. nov., Singerocomus rubriflavus gen. and sp. nov.

25. and a new combination for Xerocomus inundabilis. Mycologia 108:157-173. doi:10.3852/15-075

26. Hesse R (1891) Die Hypogaeen Deuschlands: Band I. Die Hymenogastreen. Verlag L. Hopstetter, Halle

27. Horak E (1964) Fungi austroamericani IX. Beitrag zur Kenntnis der Gattungen Gautieria Vittad., Martellia Matt. und Octavianina Kuntze in Südamerika (Chile). Sydowia 17:308-313

28. Huson DH, Bryant D (2006) Application of phylogenetic networks in evolutionaryã⿰氵studies. Mol Biol Evol 23:254-267. doi:10.1093/molbev/msj030

29. Izumitsu K, Hatoh K, Sumita T, Kitade Y, Morita A, Tanaka C, Gafur A, Ohta A, Kawai M, Yamanaka T, Neda H, Ota Y (2012) Rapid and simple preparation of mushroom DNA directly from colonies and fruiting bodies for PCR. Mycoscience 53:396-401. doi:10.1007/S10267-012-0182-3

30. Katoh K, Standley DM (2013) MAFFT Multiple Sequence Alignment Software Version 7: Improvements in Performance and Usability. Mol Biol Evol 30:772-780. doi:10.1093/molbev/mst010

31. Kuehne HA, Murphy HA, Francis CA, Sniegowski PD (2007) Allopatric divergence, secondary contact, and genetic isolation in wild yeast populations. Curr Biol 17:407-411.

doi:10.1016/j.cub.2006.12.047

32. Kuo M, Ortiz-Santana B (2020) Revision of leccinoid fungi, with emphasis on North American taxa, based on molecular and morphological data. Mycologia 112:197-211. 
doi:10.1080/00275514.2019.1685351

33. Lebel T, Orihara T, Maekawa N (2012a) The sequestrate genus Rosbeeva T.Lebel \& Orihara gen. nov. (Boletaceae) from Australasia and Japan: new species and new combinations. Fungal Divers 52:4971

34. Lebel T, Orihara T, Maekawa N (2012b) Erratum to: the sequestrate genus Rossbeevera T.Lebel \& Orihara gen. nov. (Boletaceae) from Australasia and Japan: new species and new combinations. Fungal Divers 52:73

35. Leducq JB, Nielly-Thibault L, Charron G, Eberlein C, Verta JP et al. (2016)

36. Speciation driven by hybridization and chromosomal plasticity in a wild yeast. Nature Microbiology 1:15003. doi:10.1038/NMICROBIOL.2015.3

37. Matheny PB, Liu YJ, Ammirati JF, Hall BD (2002) Using RPB1 sequences to improve phylogenetic inference among mushrooms (Inocybe, Agaricales). Am J Bot 89:688-698

38. Marcet-Houben M, Gabaldón T (2015) Beyond the whole-genome duplication: phylogenetic evidence for an ancient interspecies hybridization in the Baker's yeast lineage. PLOS Biology 13:e1002220. doi:10.1371/journal.pbio.1002220

39. Nuhn ME, Binder M, Taylor AF, Halling RE, Hibbett DS (2013) Phylogenetic overview of the Boletineae. Fungal Biology 117:479-511. doi:10.1016/j.funbio.2013.04.008

40. Nylander JAA (2004) MrModeltest v2. Program distributed by the author. Evolutionary Biology Centre. Uppsala University, Uppsala

41. Orihara T, Sawada F, Ikeda S, Yamato M, Tanaka C, Shimomura N, Hashiya M, Iwase K (2010) Taxonomic reconsideration of a sequestrate fungus, Octaviania columellifera, with the proposal of a new genus, Heliogaster, and its phylogenetic relationships in the Boletales. Mycologia 102:108-121. doi:10.3852/08-168

42. Orihara T, Smith ME, Shimomura N, Iwase K, Maekawa N (2012a) Diversity and systematics of the sequestrate genus Octaviania in Japan: two new subgenera and eleven new species. Persoonia 28:85-112. doi:10.3767/003158512X650121

43. Orihara T, Smith ME, Ge Z-W, Maekawa N (2012b) Rossbeevera yunnanensis (Boletaceae, Boletales), a new sequestrate species from southern China. Mycotaxon 120:139-147. doi:10.5248/120.139

44. Orihara T, Lebel T, Ge Z-W, Smith ME, Maekawa N (2016a) Evolutionary history of the sequestrate genus Rossbeevera (Boletaceae) reveals a new genus Turmalinea and highlights the utility of ITS minisatellite-like insertions for molecular identification. Persoonia 37:173-198. doi:10.3767/003158516X691212

45. Orihara T, Ohmae M, Yamamoto K (2016b) First report of Chamonixia caespitosa (Boletaceae, Boletales) from Japan and its phylogeographic significance. Mycoscience 57:58-63. doi:10.1016/j.myc.2015.08.005

46. Orihara T, Smith ME (2017) Unique phylogenetic position of the African truffle-like fungus, Octaviania ivoryana (Boletaceae, Boletales) and the proposal of a new genus. Afrocastellanoa Mycologia 109:323-332. doi:10.1080/00275514.2017.1301750 
47. Paz A, Vidal JM, Lavoise C, Moreau P-A (2014) Primeros datos para una revisión del género Octaviania en Europa: 0 . depauperata comb. \& stat. nov., 0 . depauperata var. laurarum var. nov. y 0 . vacekii sp. nov. Boletín Micológico de FAMCAL 9:77-97

48. Paz A, Vidal JM, Lavoise C, Moreau P-A (2016) Revisión taxonómica del género Octaviania (Boletales) en Europa. Boletín Micológico de FAMCAL 9:101-138

49. Pegler DN, Young TWK (1979) The gasteroid Russulales. Transactions of the British Mycological Society $72: 353-388$

50. Ronquist F, Huelsenbeck JP (2003) MrBayes 3: Bayesian phylogenetic inference

51. under mixed models. Bioinformatics 19:1572-1574. doi: 10.1093/bioinformatics/btg180

52. Schardl CL, Craven KD (2003) Interspecific hybridization in plant-associated fungi and

53. oomycetes: a review. Molecular Ecology 12:2861-2873. doi:10.1046/j.1365-294x.2003.01965.x

54. Singer R, Smith AH (1960) Studies on secotiaceous fungi IX. The astrogaceous

55. series. Memoirs of the Torrey Botanical Club. 21:1-112

56. 10.5598/imafungus.2015.06.02.03

Smith ME, Amses KR, Elliott TF, Obase K, Aime MC, Henkel TW (2015) New sequestrate fungi from Guyana: Jimtrappea guyanensis gen. sp. nov., Castellanea pakaraimophila gen. sp. nov., and Costatisporus cyanescens gen. sp. nov. (Boletaceae, Boletales). IMA Fungus 6:297-317. doi:10.5598/imafungus.2015.06.02.03

57. Smith ME, Castellano MA, Frank JL (2018) Hymenogaster macmurphyi and Splanchnomyces behrii are sequestrate species of Xerocomellus from the western United

58. States. Mycologia 110:605-617. doi:10.1080/00275514.2018.1465299

59. Stamatakis A (2006) RAxML-VI-HPC: maximum likelihood-based phylogenetic analyses with thousands of taxa and mixed models. Bioinformatics 22:2688-2690. doi:10.1093/bioinformatics/bt|446

60. Stenlid J, Karlsson J-O (1991) Partial intersterility in Heterobasidion annosum. Mycol Res 95:11531159

61. Stukenbrock EH (2016) The role of hybridization in the evolution and emergence of new fungal plant pathogens. Phytopathology 106:104-112. doi:10.1094/PHYTO-08-15-0184-RVW

62. Sulzbacher MA, Orihara T, Grebenc T, Wartchow F, Smith ME, Martin MP, Giachini AJ, Baseia IG (2020) Longistriata flava (Boletaceae, Basidiomycota) - a new monotypic sequestrate genus and species from Brazilian Atlantic Forest. Mycokeys 62:53-73. doi:10.3897/mycokeys.62.39699

63. Trappe JM, Castellano MA (2000) New sequestrate Ascomycota and Basidiomycota covered by the Northwest Forest Plan. Mycotaxon 75:153-179

64. Trappe JM, Molina R, Luoma DL, Cázares E, Pilz D, Smith JE, Castellano MA, Miller SL, Trappe MJ (2009) Diversity, ecology, and conservation of truffle fungi in forests of the Pacific Northwest. Gen. Tech. Rep. PNW-GTR-772. Portland, OR: U.S. Department of Agriculture, Forest Service, Pacific Northwest Research Station. 194 p. http://www.fs.fed.us/ pnw/pubs/pnw_gtr772.pdf 
65. Turner E, Jacobson DJ, Taylor JW (2011) Genetic architecture of a reinforced, postmating, reproductive isolation barrier between Neurospora species indicates evolution via natural selection. PLoS Genet 7:e1002204. doi:10.1371/journal.pgen.1002204

66. Vadthanarat S, Raspé O, Lumyong S (2018) Phylogenetic affınities of the sequestrate genus Rhodactina (Boletaceae), with a new species. R rostratispora from Thailand Mycokeys 29:63-80. doi:10.3897/mycokeys.29.22572

67. van der Hammen T (1974) The Pleistocene changes of vegetation and climate in tropical South America. J Biogeogr 1:3-26

68. Vidal JM (2004) The Genus Stephanospora Pat., two new combinations. Revista Catalana de Micologia 26:97-111

69. Vittadini C (1831) Monographia Tuberacearum. Mediolani, Milano

70. Wu G, Feng B, Xu J, Zhu XT, Li YC, Zeng NK, Hosen MI, Yang ZL (2014) Molecular phylogenetic analyses redefine seven major clades and reveal 22 new generic clades in the fungal family Boletaceae. Fungal Divers 69:93-115. doi:10.1007/s13225-014-0283-8

71. Wu G, Li YC, Zhu XT, Zhao K, Han LH, Cui YY, Li F, Xu JP, Yang ZL (2016) One hundred noteworthy boletes from China. Fungal Divers 81:25-188. doi:10.1007/s13225-016-0375-8

72. Wu G, Lee SML, Horak E, Yang ZL (2018) Spongispora temasekensis, a new boletoid genus and species from Singapore. Mycologia 110:919-929. doi:10.1080/00275514.2018.1496387

73. Yanaga K, Maekawa N, Shimomura N, Ishigaki Y, Nakamura Y, Takegami T, Tomosugi N, Miyazawa S, Kuwabata S (2012) Use of ionic liquid in fungal taxonomic study of ultrastructure of basidiospore ornamentation. Mycological Progress 11:343-347. doi:10.1007/s11557-011-0794-6

74. Yang ZL, Trappe JM, Binder M, Sanmee R, Lumyong P, Lumyong S (2006) The sequestrate genus Rhodactina (Basidiomycota, Boletales) in northern Thailand. Mycotaxon 96:133-140

\section{Tables}

Due to technical limitations, table 1 and 2 are only available as a download in the Supplemental Files section.

\section{Figures}




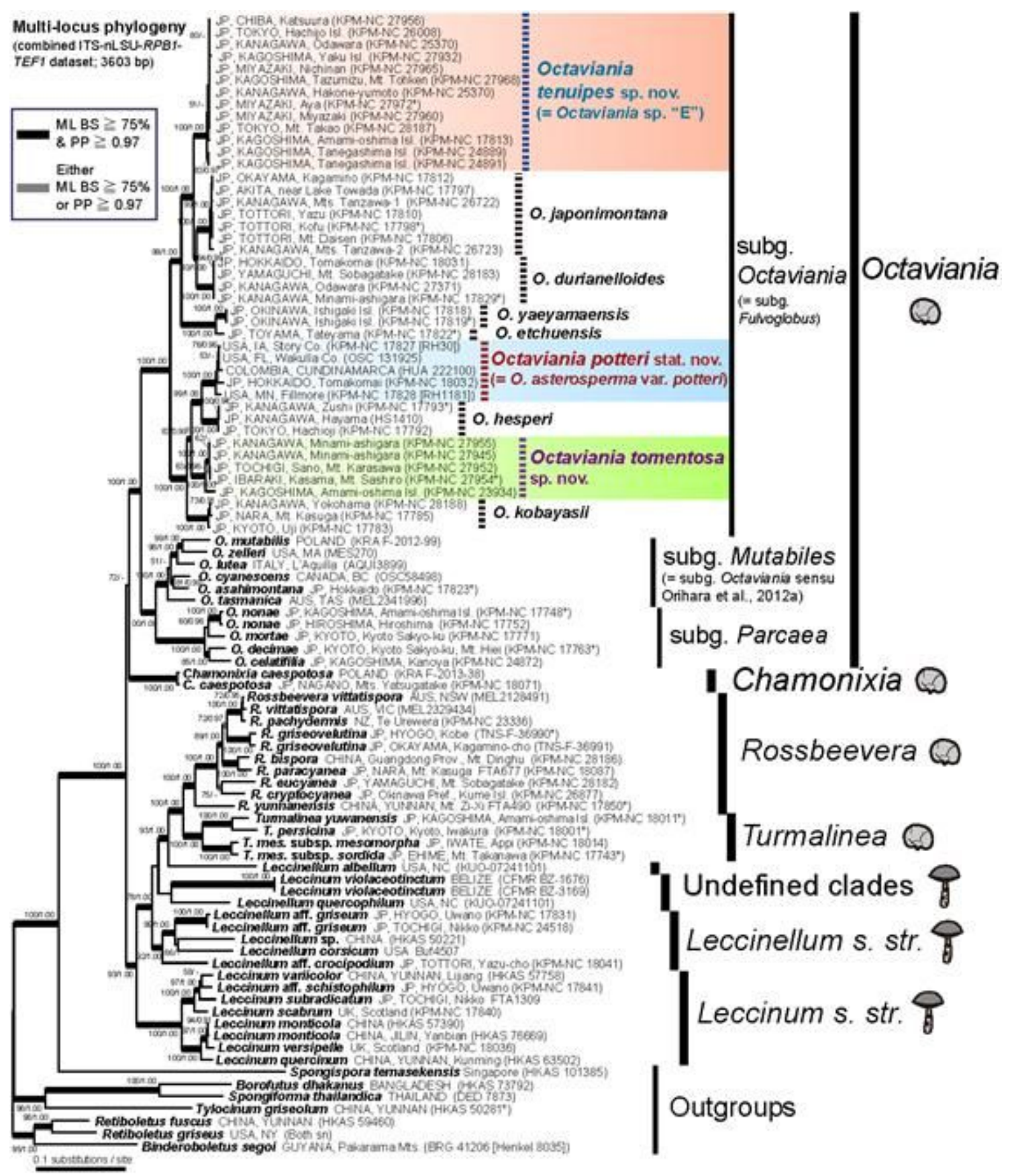

Figure 1

Maximum likelihood (ML) tree of the Leccinoideae inferred from the multi-locus (ITS and LSU nrDNA, RPB1 and TEF1) dataset. Branches supported by both BS $\geq 75 \%$ and PP $\geq 0.97$ and are depicted as thickened black lines. Branches supported by either BS $\geq 75 \%$ or PP $\geq 0.97$ are shown as thickened gray lines. Statistical values below BS $<50 \%$ or PP $<0.90$ are not shown. Holotype materials are designated with asterisks (*). Taxa outside of the core clade of Leccinoideae are used as outgroups. 


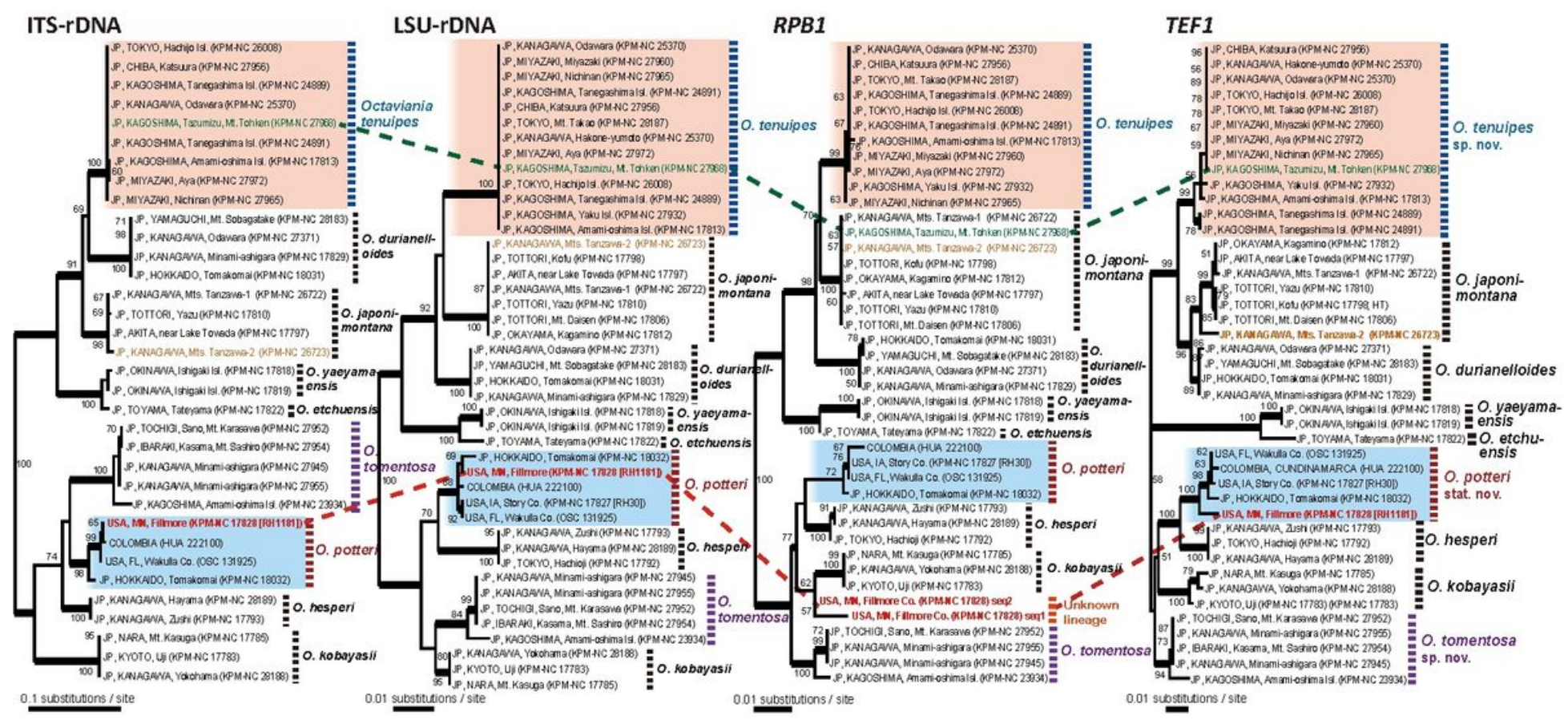

Figure 2

Comparison of four ML trees of O. subg. Octaviania based on ITS and LSU nrDNA, RPB1 and TEF1 datasets. Branches supported by BS $\geq 75 \%$ are depicted as thickened black lines. BS value below $50 \%$ are not shown. Specimens that have heterogeneous RPB1 or TEF1 sequences are depicted in coloured fonts. Octaviania potteri KPM-NC 17828 (RH1181) specimen had two highly heterogenous RPB1 sequences (i.e., "seq1" and "seq2") as shown in the red font.

O. durianelloides JP, Kanagawa Pref. (KPM-NC 27371)

O. japonimontana JP, Kanagawa Pref. (KPM-NC 27623)

JP, Kanagawa Pref. (KPM-NC 27622) $J_{99.7}$

O. tenuipes $\times 0$. japonimontana

JP, Kagoshima Pref. (KPM-NC 27968)

O. tenuipes JP, Miyazaki Pref (KPM-NC 27972*)

O. etchuensis

JP, Toyama Pref. (KPM-NC 17822*)

O. yaeyamaensis JP, Okinawa Pref.,

Ishigaki IsI. (KPM-NC 17818)
O. kobayasii JP, Nara Pref. (KPM-NC 17785)

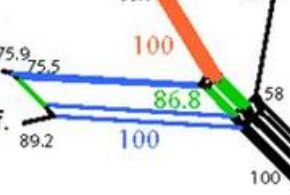

O. potteri $\times$ Octaviania unknown lineage

O. tomentosa JP, Kanagawa Pref.

(KPM-NC 27945)

O. tomemtosa JP, Kagoshima Pref,
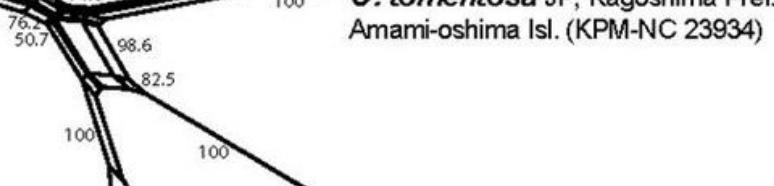

O. hesperi JP, Kanagawa Pref. (KPM-NC 28189)

USA, MN, Fillmore Co. (KPM-NC 17828) 
Phylogenetic network of the combined multi-locus (ITS and LSU nrDNA, RPB1 and TEF1) dataset of 0. subg. Octaviania constructed by the NeighborNet method and displayed with the EqualAngle algorithm (Dress and Huson 2004). BS values below 50\% are not shown. Holotype materials are designated with asterisks (*).
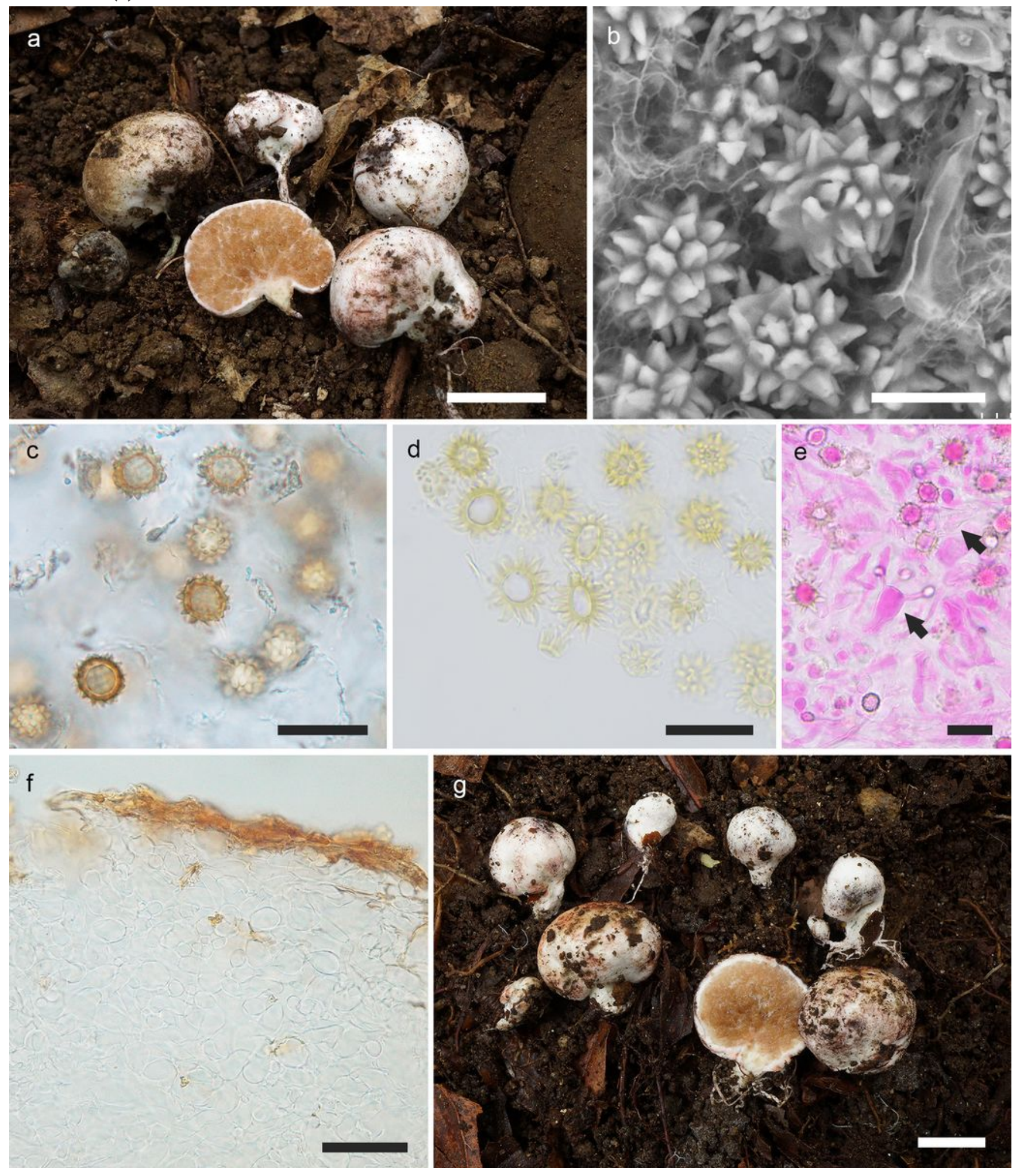

Figure 4 
a-f Octaviania tenuipes. a Basidiomata (holotype [KPM-NC 27972]). b Basidiospores under SEM (holotype). c Basidiospores mounted in water (KPM-NC 27957). d Basidiospores with elongated ornamentation mounted in lactic acid after pre-soaking in $3 \% \mathrm{KOH}$ (holotype). e Basidia (arrows) and basidiospores mounted in $3 \% \mathrm{KOH}$ after staining with $1 \%$ phloxine (holotype). f Peridium (holotype). g Basidiomata of O. japonimontana (KPM-NC 27623). Topological comparison among gene trees reveals that this specimen has a remarkably divergent TEF1 sequence from those of other 0 . japonimontana specimens (Fig. 2). Scale bars: $a, g=1 \mathrm{~cm}, b=10 \mu \mathrm{m}, c-e=20 \mu \mathrm{m}, \mathrm{f}=50 \mu \mathrm{m}$.
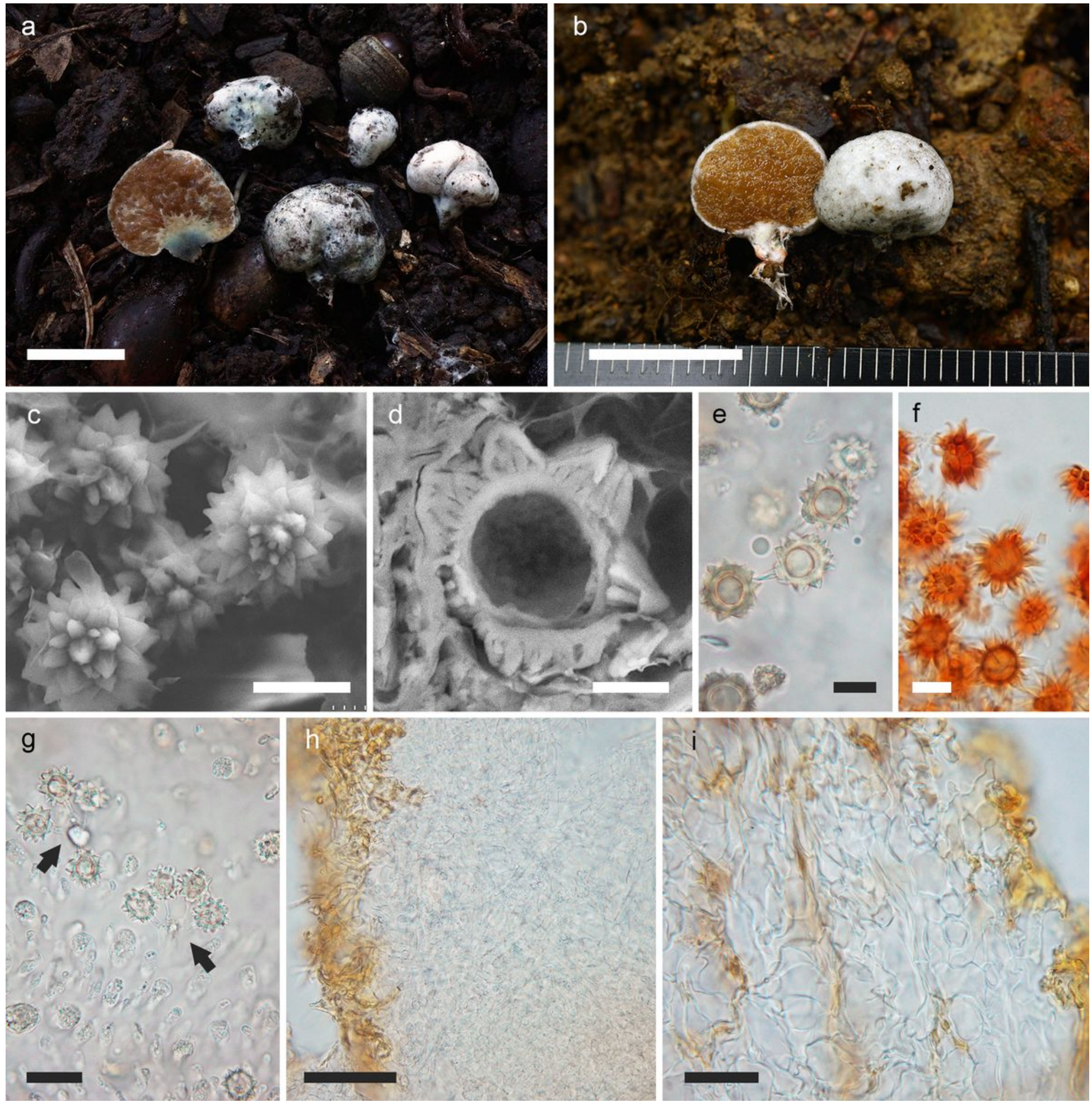

Figure 5 
Octaviania tomentosa. a-b Basidiomata (a holotype from central Honshu, Japan [KPM-NC 27954]; b specimen from Amami-oshima Island, Japan [KPM-NC 23934]). c Basidiospores under SEM (holotype). d section of a basidiospore showing multiple slit-like cavities inside the spiny ornaments. e Basidiospores mounted in water (KPM-NC 27945). $f$ Dextrinoid basidiospores with elongated ornamentation mounted in lactic acid after pre-soaking in Melzer's reagent (KPM-NC 23934). g Basidiospores connected to 4-spored basidia (arrows; KPM-NC 27955). h Peridium of an immature basidiome (KPM-NC 27955). i Peridium of a mature basidiome (KPM-NC 27953). Scale bars: $a-b=1 \mathrm{~cm}, c, e-f=10 \mu \mathrm{m}, d=5 \mu \mathrm{m}, \mathrm{g}, \mathrm{i}=20 \mu \mathrm{m}, \mathrm{h}=50$ $\mu \mathrm{m}$.
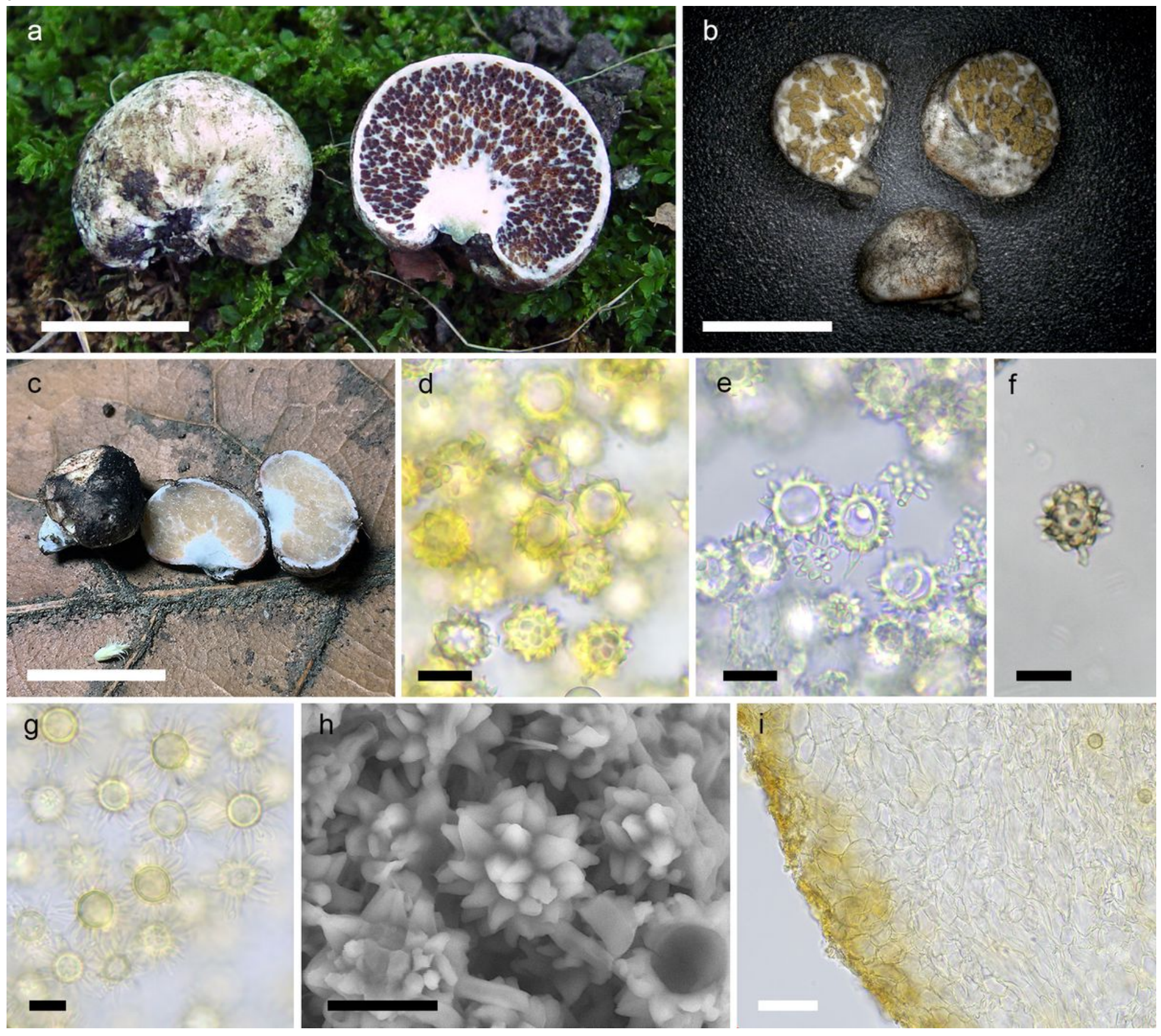

Figure 6

Octaviania potteri. a-c Basidiomata (a FH 00284311 [RH30; duplicate: KPM-NC 17827] from lowa, USA; b KPM-NC 18032 from Hokkaido, Japan; c HUA 222100 from Cundinamarca Province, Colombia). d-f 
Basidiospores mounted in water (d KPM-NC 17827 [RH30]; e KPM-NC 17828 [RH1181; a potential hybrid specimen between 0 . potteri and a closely related unknown species]; f holotype [MICH 12376]). $\mathrm{g}$ Basidiospores mounted in lacto-glycerol after pre-soaking in 3\% $\mathrm{KOH}$ and water (MES807 [FLAS-F66548]). h Basidiospores under SEM (FLAS-F-62022). i Peridium (MES807 [FLAS-F-66548]). Scale bars: a, $\mathrm{c}=1 \mathrm{~cm}, \mathrm{~b}=5 \mathrm{~mm}, \mathrm{~d}-\mathrm{h}=10 \mu \mathrm{m}, \mathrm{i}=50 \mu \mathrm{m}$.

\section{Supplementary Files}

This is a list of supplementary files associated with this preprint. Click to download.

- Table1Specimensforphylogeneticanalyses.xlsx

- SuppIFigS10ctavianiaRAxMLLSUOriharaetal..pdf

- Table2ComparisonofsporesofOctavianiapotteri.xlsx 